\title{
Coordination in heterogeneous federal systems ${ }^{\text {th }}$
}

\section{Antoine Loeper $*$}

Managerial Economics and Decision Sciences, Kellogg School of Management, Northwestern University, United States

\author{
JEL classification: \\ D62 \\ D72 \\ H70 \\ H73 \\ Keywords: \\ Federalism \\ Decentralization \\ Coordination \\ Externality \\ Reciprocality \\ Harmonization \\ Law \\ Regulation
}

\begin{abstract}
A B S T R A C T
We compare centralized and decentralized policy making in a federation in which policy heterogeneity is inherently costly and preferences vary across jurisdictions: all jurisdictions agree that some harmonization is desirable but no one agrees on the direction of harmonization. This type of collective choice problem arises when members of a federal system have to coordinate nonbudgetary policies such as laws, regulations, standards, or diplomatic policies. Contrary to the common wisdom, decentralization becomes optimal when coordination becomes very important. When coordination costs are symmetric, decentralization dominates centralization irrespective of the magnitude of externalities and the heterogeneity of preferences. In the case of discontinuous network effects, standardization never Pareto dominates decentralization.
\end{abstract}

\section{Introduction}

The optimal allocation of responsibilities in federal systems is the subject of continuing debates which span virtually every policy domain. Since the seminal work of Oates (1972), the fiscal federalism literature has analyzed the case of tax and expenditure externalities generated by local public goods, tax competition, or environmental policies. It has shown that the comparison between centralization and decentralization boils down to a trade off between the internalization of cross border externalities and the responsiveness to local prefer ences. Its central normative conclusion, the Oates Decentralization Theorem, states that the costs and benefits of fiscal decentralization hinges on the magnitude of externalities and the heterogeneity of preferences.

Although this theorem has been invoked in various policy domains (e.g., Coeure and Pisani Ferry, 2003; Alesina et al., 2005a, 2005b), so

\footnotetext{
is I wish to thank David Austen-Smith, Helmuth Cremer, Jacques Crémer, Daniel Diermeier, Bard Harstad, Michel Lebreton, and seminar participants at the 2005 European Meeting of the Econometric Society in Istanbul, the 2006 CORE summer school in Louvain La Neuve, the 2008 Midwest Economics Association Annual Meeting in Chicago, the 2008 EEA congress in Milan, the 2008 SITE workshop in Stanford for helpful comments. All remaining errors are mine.

* Tel.:+1 8474915347.

E-mail address: a-loeper@kellogg.northwestern.edu.
}

far, few models have been proposed to extend it beyond the fiscal and environmental spheres. As noted by Ellingsen (1998) (p. 266), "the study of laws, regulations and standards may require a different model." This paper builds a simple model which compares central ization and decentralization when local policies are laws, regulations, or standards rather than tax rates or local public goods. The starting point of our analysis is that the externalities generated by these nonbudgetary policies, which we call coordination externalities, are of a different nature than fiscal spillovers. While fiscal externalities induce a prisoner's dilemma, which typically results in a race to the bottom, coordination externalities induce a novel collective choice problem closer to the battle of the sexes, ${ }^{1}$ which results in a race to local particularism: all jurisdictions agree that some harmonization is desirable but no one agrees on the direction of harmonization. Our main finding is that the comparative statics of the decentralization debate are qualitatively different from the received wisdom and make a stronger case for decentralization.

While fiscal externalities depend on the level of taxes or public spending in the neighboring jurisdictions, coordination externalities are driven by the differences and incompatibilities between local policies. These externalities can take various forms: heterogeneous

\footnotetext{
${ }^{1}$ See Fudenberg and Tirole (1991) (p. 18) for a presentation of the battle-ofthe-sexes.
} 
legal systems generate transaction costs, legal uncertainty, litigation costs, and duplication of drafting costs. Heterogeneous regulations such as accounting norms, safety standards, or governance rules increase compliance costs for international firms. The negative impact of legal and regulatory fragmentation on trade, competition, and cross border cooperation is now well documented. An OECD study has estimated that up to $80 \%$ of trade is affected by the heterogeneity of standards or associated technical regulations. ${ }^{2}$ According to Rodrik (2004), transaction costs between advanced countries are of the order of $40 \%$ in ad valorem terms, of which only $5 \%$ are due to tariffs and the remaining 35\% are due to the "diversity of national institutional arrangements." In the EU, Kox et al. (2005) have estimated that removing regulation heterogeneity could boost the trade of services by 30 to $60 \%$. Coordination externalities are not limited to nontariff barriers to trade: heterogeneous school calendars, academic curricula, and official languages limit population mobility and labor market efficiency. In international relations, the inability of the European states to speak with a single voice on diplomatic matters has illustrated on several occasions the detrimental effect of having inconsistent foreign policies.

In this model, under decentralization, heterogeneous preferences, together with coordination externalities, result in insufficient policy harmonization, which is consistent with the view of many federal administrators and international institutions. The rationale, as high lighted by Snidal (1985) or Garoupa and Ogus (2006), is that jurisdictions free ride on efforts toward convergence. A natural remedy for this coordination failure is to impose a uniform policy. Since the information on local preferences is typically decentralized or unverifi able, standardization may be the only way for jurisdictions to reduce policy heterogeneity. However, the benefits of complete harmonization must be balanced against the inadequacy of a one size fits all policy.

This paper investigates under which conditions imposing a uniform rule can be socially beneficial. The results are in sharp contrast with the literature on fiscal and environmental spillovers. First, if coordination externalities are symmetric, decentralization dominates any uniform policy regardless of the magnitude of externalities or the heterogeneity of preferences. The intuition is that if externalities are symmetric, local jurisdictions internalize half of the social cost they impose on the federation, which mitigates the consequences of non cooperative behavior. Second, the cost of decentralization vanishes as coordination externalities become sufficiently severe: contrary to the standard public good setup, when coordination is crucial, the pursuit of self interested policies by local jurisdictions results in a degree of policy harmonization which leaves little need for a federal intervention.

These results, derived under standard institutional assumptions, show that the merit of decentralization hinges critically on the nature of cross border externalities i.e., whether external costs are driven by legal distances and policy incompatibilities as in this paper, or by policy levels as in the fiscal federalism scenario. For instance, one should not think of the centralization of education expenditures in the same terms as the harmonization of school curricula. Similarly, the centralization of police expenditures should not be justified by the same criteria as criminal law codification. Likewise, the harmoniza tion of corporate tax rates and the standardization of accounting norms should not proceed from the same logic. When the fiscal prisoner's dilemma turns into an administrative or legislative battle of the sexes, a greater interdependence and a greater need for coordination may not justify a federal intervention.

The paper is organized as follows. Section 3 lays out the model. Section 4 derives our main results. Section 5 analyzes the case of discontinuous network effects and Section 6 concludes. All proofs are relegated to Appendix A.

\footnotetext{
2 "Regulatory Reform and International Standardization," Paris: OECD Working Party of the Trade Committee, 1999.
}

\section{Related literature}

The majority of the economic literature on federalism has focused on fiscal and environmental externalities, as in the seminal contribu tions of Oates (1972); Gordon (1983); Zodrow and Mieszkowski (1986), and Wilson (1986). The central normative result, the Oates Decentralization Theorem, states that greater externalities and/or more homogeneous preferences make the case for centralization. ${ }^{3}$ Both comparative static results do not hold in the collective choice problem analyzed in this paper. Moreover, our results show that the precise patterns of interjurisdictional externalities are more impor tant than their magnitude. Lockwood (2002) and Besley and Coate (2003) show in fiscal federalism setups that the Decentralization Theorem may fail because of political economy distortions. In our case, it fails even under standard institutional assumptions.

One might at first think that the discrepancy between fiscal federalism models and this one comes from the fact that fiscal spillovers are driven by policy levels while coordination externalities are driven by policy differences. However, in some models of fiscal federalism for instance, tax competition with mobile factors (Bucovetsky et al., 1998) or redistribution with population mobility (Brown and Oates, 1987; Wildasin, 1991) policy heterogeneity is inherently socially suboptimal as in our setup. ${ }^{4}$ However, these models are not strategically equivalent to ours because the distributional impact of heterogeneous policies on local jurisdiction is not the same. In the fiscal competition case, only the high tax jurisdiction suffers from the tax differential: the welfare of a given jurisdiction $i$ is typically decreasing in the tax level of another jurisdiction $j$. In the coordination case, both jurisdictions suffer from the difference between their policies: the welfare of jurisdiction $i$ is unimodal in $x_{j}$ with a maximum at $x_{j}=x_{i}{ }^{5}$

The law literature has documented the costs generated by heterogeneous laws, ${ }^{6}$ and also the cost of legal harmonization due to the heterogeneity of legal cultures and social customs. ${ }^{7}$ The comparative law literature and the law and economics literature have investigated whether increasing economic integration and competition between legal systems will eventually result in legal convergence, and whether legal convergence is socially desirable. ${ }^{8}$ With the exception of Garoupa and Ogus (2006), who study a two country two action model, the normative literature on legal harmonization typically take existing legal systems as fixed and qualitatively compares the costs generated by their heterogeneity to the cost of a one size fits all legal code. Our equilibrium analysis suggests that the incentive faced by local policy

\footnotetext{
${ }^{3}$ See Farber (1997); Oates (1999) or Epple and Nechyba (2004) for a literature review. See also Alesina and Spolaore (1997); Redoano and Scharf (2004) and Alesina et al. (2005) for a political economy perspective on the tension between heterogeneity and centralization.

${ }^{4}$ An equilibrium in a model of fiscal competition with nonuniform capital tax rates (e.g., because of heterogeneous fiscal needs) is typically inefficient because differences in pre-tax returns imply an inefficient allocation of capital. In the case of population mobility, policy heterogeneity is inefficient because of the mobility costs it generates.

${ }^{5}$ The preferences of a jurisdiction $i$ on $x_{i}$ are similar in both setups: the bestresponse functions typically exhibit strategic complementarities (Laussel and Le Breton, 1998) so the equilibrium correspondences are similar. However, the preferences of jurisdiction $i$ on $x_{j}$ (i.e. the externality effect) are different. For this reason, the equilibrium welfare analysis is different. I am grateful to a referee for raising this point.

${ }^{6}$ On the benefits of legal harmonization, see Markesinis (1994); Lando (2000), or Marciano and Josselin (2002) (an edited volume of contributions on the topic).

7 See Daniels (1991) on Canada, Ribstein and Kobayashi (1996) on the U.S., Legrand (1997) on the E.U. and Black et al. (2000) on Russia. Mattei (1994); Teubner (1998), and Berkowitz et al. (2003) analyze the efficiency and responsiveness to local conditions of legal transplants.

${ }^{8}$ Mattei (1997) and Zweigert and Kötz (1998) are standard references on comparative law. On legal convergence, see Berman (1965) on international sales law, Hansmann and Kraakman (2001) on corporate governance, Legrand (1996) on the E.U. and Smythe (2008) on the uniform sales act in the U.S. Garoupa and Ogus (2006) and Carbonara and Parisi (2007) propose game-theoretic models of legal convergence.
} 
makers will result in a satisfactory degree of voluntary harmonization regardless of the relative magnitude of these costs.

Baniak and Grazl (2009) have independently developed a similar model of harmonization of legal standards. It differs from ours in that jurisdictions are ex ante identical and the authors focus on the impact of information dispersion. Despite these differences, they show that decentralization dominates centralization under a symmetry condi tion similar to ours.

In international relations, Snidal (1985) and Mattli and Büthe (2003), among others, have argued that certain conflicts of interest are better described by coordination games than by the prisoner's dilemma. Finally, in organization theory, Alonso et al. (2008) and Rantakari (2008) analyze strategic communication in a coordination game similar to ours and show that a greater need for coordination improves the quality of communication under decentralization.

\section{The model}

We consider a finite set $I$ of jurisdictions which can be variously interpreted as countries, members of a federation, localities, or even individuals in a community. The welfare of the residents of jurisdiction $i$ is denoted by $U_{i}$. As a social ordering criterion, we use the Benthamite social welfare function $B=\sum_{i} \omega_{i} U_{i}$, where $\omega_{i}$ is the social weight of jurisdiction $i$.

\subsection{Policies and preferences}

In line with the existing literature on federalism, our model relies on two key ingredients: heterogeneous local preferences and interjurisdictional externalities. We focus on a class of externalities, henceforth coordination externalities, whose magnitude depends on the differences between policies.

As we will see in Subsection 3.2, the types of policies that generate coordination externalities cover a wide range of public issues. To encompass these various situations, we cast our argument in an abstract setting where the policy space $X$ is $\mathbb{R}^{k}$. An alternative is a vector of local policies $x$ and $x_{i} \in X$ refers to the policy of jurisdiction $i$. We interpret the Euclidean distance $\left\|x_{i}-x_{j}\right\|$ as the degree of similarity or compatibility between $x_{i}$ and $x_{j}$ (the "legal distance" in Carbonara and Parisi, 2007). For multifaceted policies composed of a large number of discrete components, the distance between two policies can be interpreted as the number, or the proportion of (possibly weighted) items on which they differ (see Kox et al., 2005 and Carbonara and Parisi, 2007). The welfare of the citizens of jurisdiction $i$ is given by:

$U_{i}(x)=V_{i}\left(x_{i}\right)-\sum_{j \neq i} \beta_{i, j} W\left(\left\|x_{i}-x_{j}\right\|\right)$,

where the function $W: \mathbb{R}^{+} \rightarrow \mathbb{R}$ is weakly increasing and, by convention $W(0)=0$. Hence, all jurisdictions agree that some harmonization is desirable but each jurisdiction $i$ has a distinct ideal policy given by $\arg \max V_{i}$.

The term $\beta_{i, j} W\left(\left\|x_{i}-x_{j}\right\|\right)$ is the coordination externality borne by jurisdiction $i$ for having a policy which is different from that of jurisdiction $j$. The term $V_{i}\left(x_{i}\right)$ embodies the intrinsic preferences of jurisdiction $i$, i.e., whether its local policy meets the specific needs of its residents. If we assume that before the federation was formed, the policy of each jurisdiction $i$ was $\arg \max V_{i}$ and jurisdictions were independent of each other $(\beta \equiv 0)$, then $V_{i}\left(x_{i}\right)$ can alternatively be interpreted as the adaptation cost borne by jurisdiction $i$ for changing its policy from $\arg \max _{i}$ to $x_{i}$ : the cost of re drafting the law, adapting pre existing enforcement rules, reforming institutions, and the loss of legal coherence with other domestic laws.

The externality matrix $\beta=\left(\beta_{i, j}\right)_{j \neq i}$ introduces relational hetero geneity to allow for a variety of patterns of interdependence between jurisdictions. These patterns can reflect the networks of bilateral trade, exchanges or cooperation projects between local jurisdictions. The profile $\left(V_{i}\right)_{i \in I}$ introduces idiosyncratic heterogeneity to take into account the variety of local circumstances and preferences across jurisdictions. These variations may be due to differences in legal cultures, social customs, and pre existing rules and institutions (Legrand, 1996; Teubner, 1998; Black et al., 2000; Berkowitz et al., 2003); income (Ganuza and Gomez, 2008); or stage of development (Trubek and Galanter, 1974; Djankov et al., 2003, Rodrick 2004).

The welfare performance of centralization and decentralization obviously depend on the shape of $W$. In Section 4, we consider the case of smooth externalities, i.e., coordination costs that are small when policies are sufficiently similar and that increase gradually as policies become more heterogeneous. This can be the case of policies which have a natural distance (e.g., time zones and criminal sentences) or which comprise a large number of items (e.g., a body of law or a complex regulation). In Section 5, we extend the analysis to the opposite case of coordination costs which jump discontinuously as policies become slightly different. This assumption is more natural for technological standards, dichotomous decisions, or public services whose standardization allows for economies of scale.

\subsection{Coordination externalities}

In this subsection, we discuss examples of laws and policies which generate coordination externalities. Nonuniform state laws on consumer protection (packaging and labeling regulations, regulations on the quality of professional services) generate uncertainty and informational costs for consumers who buy imported goods and services, or shop across borders. Variations in product liability increase litigation costs by encouraging forum shopping; it gives a sense of unfairness which is detrimental to law enforcement. ${ }^{9}$ The latter point applies more generally to most penal laws and is at the root of the U.S. Sentencing Reform Act, which harmonizes penal sentences in order to "provide certainty and fairness" while "avoiding unwarranted sentencing disparities" ${ }^{10}$ Nonuniform consumer pro tection rules, accounting norms, or governance rules also increase legal uncertainty and compliance costs for firms which produce or invest in different jurisdictions (Kox et al., 2005). Likewise, hetero geneous default rules in contract law make it harder for contracting parties to infer what might happen in case of disputes or unforeseen contingencies. This unpredictability can only be mitigated through costly information acquisition or by making the contract excessively detailed, which limit the gains from trade. ${ }^{11}$ These barriers to trade increase consumer switching costs, reduce competition within each state, limit the spread of markets and thus decrease consumer welfare.

Coordination costs are not confined to the legal and regulatory spheres. Distant time zones make cross border cooperation harder. Incompatibilities of technical standards hamper the efficiency of global supply chains. Miscoordinated demand management policies can be counterproductive (Gordon and Pelkmans, 1979). The harmonization of cultural policies through, for instance, a common official language or a uniform elementary and secondary school system, creates a commonality of experience and a sense of community. ${ }^{12}$ A common academic architecture at the university level increases student mobility and competition in the education market. The standardization of certain types of public services

\footnotetext{
${ }^{9}$ For standard references on the cost of legal heterogeneity, see Section 2.

10 U.S. Code, Chapter 58, section 991: United States Sentencing Commission; establishment and purposes.

${ }^{11}$ A choice-of-law clause does not eliminate these issues completely because certain types of breaches allow the court to change the choice-of-law rule. Moreover, there might not be a jurisdiction whose law satisfies both parties.

12 On the effect of diversity on the formation of a national identity, see Hurlburt (1987).
} 
(telecommunication and military equipment) can economize on fixed costs (Mattli and Büthe, 2003). In some localities, zoning laws regulate the details of facade design to guarantee the harmony of the streetscape. As for foreign policies, the inability of a federation to speak with a single voice limits its bargaining power in international fora (Coeure and Pisani Ferry, 2003; Smaghi, 2004) or when negotiating with another country, as is illustrated by Russia's use of energy security to divide and rule European states (Bressand, 2010). ${ }^{13}$ Diverging positions on the location of common borders, the naming of shared seas, the recognition of independence of other countries, or the historical record of past events can strain diplomatic relations, as illustrated by the controversy over the naming of the sea of Japan or the treatment of World War II in Japanese history textbooks (Ienaga, 1993; Beal et al., 2001).

\subsection{Centralization and decentralization}

We assume that under decentralization, local governments maximize the welfare of their respective constituencies but do not internalize the impact of their decisions on the rest of the federation. Formally, a decentralized equilibrium is a (pure strategy) Nash equilibrium of the noncooperative game in which the set of players is the set of jurisdictions $I$, the strategy of each jurisdiction $i \in I$ is its local policy $x_{i} \in X$ and its payoff $U_{i}$ is the welfare of its residents as given in Eq. (1). ${ }^{14}$

Under centralization, policies are assumed to be uniform across all jurisdictions. Since our results give conditions under which decen tralization is socially preferred to any uniform policy, we do not have to specify the mechanism used to select the centralized policy.

The uniformity assumption reflects the managerial intuition that more centralized organizations exhibit more rigidity. It has been the workhorse of most of the federalism literature. Its lack of theoretical foundation has recently been criticized by several authors. ${ }^{15}$ Below, we explain why unitarian centralization is a relevant scenario in our setup, more so than in fiscal federalism.

Empirically, numerous nonbudgetary policies and laws have been completely standardized, either voluntarily (the Merchant Law in medieval Europe, the Uniform Sales Act in the U.S., or the recent joint French German history textbook), through directives (the Common Technical Regulation in the EU.), or by federal legislation (the common time zone in China, international trade and monetary policies in the U.S. and in the EU.).

Second, globalization and the increasing interdependence of economies have made regulatory and legislative harmonization more popular among federal administrators ${ }^{16}$ and international institutions. ${ }^{17}$ The calls for a European civil code or for the unification of the external representation of the EU proceed from the same logic. ${ }^{18}$ The appeal of a single rule is that it removes all coordination costs. Hence, contrary to the case of local public goods, policy harmonization is beneficial per se in our setup.

\footnotetext{
13 The idea that internal divisions can affect the bargaining power of a group of states goes back to the literature on two level games (Putnam, 1988). See Meunier (2000) for a different perspective and more recent references.

14 Alternatively, $U_{i}$ can be viewed as the welfare of the median voter in jurisdiction $i$

15 See, e.g., Cremer, Estache and Seabright (1996); Seabright (1996); Qian and Weingast (1997); Lockwood (2002); Besley and Coate (2003); Oates (2005); Harstad (2007), or Loeper (2008).

16 The 2008 U.S. Treasury Blueprint for a Modernized Financial Regulatory Structure states (p. 126): "The lack of regulatory uniformity in the U.S. in a time of increasing convergence and globalization has caused many insurers to question the effectiveness and efficacy of state regulation." Section 4 of the Canada Business Corporations Act (1985) reads: "the purposes of this act are ... to advance the cause of uniformity of business corporation law in Canada."

17 The Agreement on Technical Barriers to Trade of the W.T.O. states that "where technical regulations are required and relevant international standards exist ... members shall use them ... as a basis for their technical regulations."

18 See e.g. Strauss-Kahn (2002) or Smaghi (2004).
}

By the same token, while agency costs at the federal level result in an unequal allocation of federal funds for local projects (Lockwood, 2002; Besley and Coate, 2003; Solé and Sorribas, 2007), they create harmonization forces in our setup: whether she ignores local information (Baniak and Grazl, 2009; Loeper, 2008), favors a member of the federation, or wants to promote federal goals at the expenses of local needs, a federal policy maker would prefer uniform policies. As noted by Farber, 1997 (p.1289), "overzealous free trade tribunals may push too hard for uniformity."

\section{Decentralization theorems}

In line with Carbonara and Parisi (2007) or Baniak and Grazl (2009), in this section we assume that the welfare of jurisdictions, as specified in Eq. (1), is differentiable and strictly convex in $x$.

A convex function $W$ corresponds to coordination costs which are small when policies are sufficiently similar and which grow increasingly rapidly as local policies differ more significantly. This assumption has a straightforward interpretation for simple policies such as setting time zones or speed limits. As argued earlier, for complex, multifaceted policies such as the selection of default rules in contract law or school curricula, the Euclidean distance in Eq. (1) can be interpreted as the number of items on which two policies differ. In that case, the convexity requirement means that each additional difference between two policies generates increasingly large coordi nation costs. Although the convexity of coordination costs allows us to derive stronger results, we show in Subsection 4.4 that the main qualitative insights of our model extend to the case of smooth but nonconvex externalities.

As argued in Subsection 3.1, $V_{i}$ can be interpreted as the adaptation cost borne by jurisdiction $i$ to change its policy to make it more compatible with that of its neighbors. In the case of laws, the convexity of $V_{i}$ means that a partial harmonization requires small adaptation costs but transplanting a foreign law from a country with widely different institutions and legal culture would either be ineffective or require deep institutional reforms. ${ }^{19}$ In the case of school curricula, it means that incremental changes would require teachers only to modify the material of a few classes but more numerous and substantial changes would require to reform the training programs of teachers, write new textbooks, and adapt college curricula. $^{20}$

For technical reasons, throughout this section, we add the following minor assumption which roughly means that intrinsic preferences are decreasing in all directions outside a bounded set.

Assumption 1. For all $i \in I$ and all $v \in X$, there exists $a \in \mathbb{R}$ such that $x_{i}$. $v \geq a$ implies $\nabla V_{i}\left(x_{i}\right) . v<0$.

To sharpen our results, we will occasionally use the following assumptions:

Definition 1. Intrinsic preferences are Euclidean if for all $i \in I, V_{i}\left(x_{i}\right)=$ $V\left(\left\|x_{i}-\theta_{i}\right\|\right)$ for some $\theta \in X^{|I|}$ and some function $V: \mathbb{R}^{+} \rightarrow \mathbb{R}$ such that $V^{\prime}(0)=0$ and $V^{\prime \prime}<0$. Preferences are furthermore quadratic if for all $i$,

$U_{i}(x)=-\left\|x_{i}-\theta_{i}\right\|^{2}-\sum_{j \neq i} \beta_{i, j}\left\|x_{i}-x_{j}\right\|^{2}$.

\footnotetext{
19 See Trubek and Galanter (1974); Mattei (1994); Teubner (1998); Black et al. (2000) or Berkowitz et al. (2003) on the successes and failures of legal transplants as a function of their responsiveness to local needs and preferences.

${ }^{20}$ Notice that the usual justification for the convexity of the production function applies also to coordination and adaptation costs: to reduce the costs of policy heterogeneity policy makers are more likely to harmonize first the parts of their policy that reduce the most coordination costs $(W)$ and generate the least adaption costs $(V)$. That means that the marginal reduction in coordination costs due to additional harmonization efforts decreases as policies become more harmonized while the marginal adaptation cost increases.
} 
Proposition 1. A decentralized equilibrium exists. It is Pareto inefficient whenever $\arg \max \left(V_{i}\left(x_{i}\right)\right)$ is not the same for all jurisdictions.

In the case of two jurisdictions with Euclidean intrinsic preferences such that $\theta_{1} \neq \theta_{2}$, for any Pareto efficient policy $x^{*}$ and any decentralized equilibrium $x^{\text {dec }},\left\|x_{1}^{*}-x_{2}^{*}\right\|<\left\|x_{1}^{\text {dec }}-x_{2}^{\text {dec }}\right\|$.

Under decentralization, coordination externalities are not inter nalized: as in Garoupa and Ogus (2006), each jurisdiction free rides on the harmonization efforts of its neighbors, which triggers a race to local particularism. Consequently, the cost of decentralization takes the form of a lack of policy harmonization. Alternatively, a uniform policy removes coordination costs but may not reconcile the interests of heterogeneous jurisdictions. We end up with a classic trade off between meeting local needs and internalizing externalities.

The following conditions will be the main determinants of the comparative advantage of centralization and decentralization.

Definition 2. Externalities are reciprocal if, for all $i \neq j, \omega_{i} \beta_{i, j}=\omega_{j} \beta_{j, i}$.

They are sufficiently elastic if, for all $d \in \mathbb{R}^{+}, \frac{W^{\prime}(d) d}{W(d)} \geq 2$.

They are sufficiently inelastic if, for all $d \in \mathbb{R}^{+}, \frac{W^{\prime}(d) d}{W(d)} \leq \varepsilon$ for some $\varepsilon<2$.

With evenly populated jurisdictions, externalities are reciprocal whenever the matrix $\beta$ is symmetric, that is when the differences between the policies of two jurisdictions impose the same cost on both of them. In the general case, the more populated region should impose a proportionally greater externality.

The elasticity $\frac{W^{\prime}(d) d}{W(d)}$ measures the relative rate of increase of coordination costs as policies get farther apart. It is related to the degree of convexity of coordination costs: if $W(d)=d^{\alpha}$, then externalities are sufficiently elastic (inelastic) if and only if $\alpha \geq 2$ $(<2)$. Observe that the notions of reciprocality and elasticity are orthogonal to the magnitude of externalities.

\subsection{The reciprocality of externalities}

The following proposition shows that reciprocal externalities make decentralization socially superior independently of the magni tude of externalities and the heterogeneity of intrinsic preferences.

Proposition 2. If externalities are reciprocal and sufficiently elastic, decentralization is socially preferred to any uniform policy.

The intuition is that reciprocal externalities impose some congruence between private and social coordination costs: if $\omega_{i} \beta_{i}$, ${ }_{j}=\omega_{j} \beta_{j, i}$, the coordination cost suffered by jurisdiction $i, \omega_{i} \beta_{i, j} W\left(\| x_{i}-\right.$ $\left.x_{j} \|\right)$, is half of the total coordination costs $\left(\omega_{i} \beta_{i, j}+\omega_{j} \beta_{j, i}\right) W\left(\left\|x_{i}-x_{j}\right\|\right)$ involving $i$ and $j$. Hence, jurisdiction $i$ internalizes half of the social cost. As a result, decentralized decision making achieves a satisfactory balance between policy coordination and responsiveness to local circumstances.

More formally, if externalities are reciprocal, non cooperative decentralization is a potential game (Monderer and Shapley, 1996): all jurisdictions maximize the same potential function

$P(x)=\sum_{i} \omega_{i} V_{i}\left(x_{i}\right)-\frac{1}{2} \sum_{i} \sum_{j \neq i} \omega_{i} \beta_{i, j} W\left(\left\|x_{i}-x_{j}\right\|\right)$.

The potential $P$ differs from the social welfare $B$ only through the weight of the double sum (the external effects) which is twice as small as in $B$.

In Subsection 4.3, we discuss in more detail the elasticity condition of Proposition 2 and show that it cannot be dispensed with. However, in Subsection 4.4 we show that the reciprocality of externalities makes the case for decentralization stronger even when the elasticity condition is not satisfied.

The next proposition shows that some degree of reciprocality is necessary as well for decentralization to dominate centralization.

Proposition 3. If preferences are quadratic, decentralization is socially preferred to any uniform policy for all profiles of types $\theta$ if and only if

for all $i, \sum_{j \neq i}\left(\omega_{j} \beta_{j, i}-\omega_{i} \beta_{i, j}\right) \leq \omega_{i}$.

Since $\sum_{i} \sum_{j \neq i}\left(\omega_{j} \beta_{j, i} \quad \omega_{i} \beta_{i, j}\right)=0$ for all $\beta$ and $\omega$, condition (4) means that the aggregate asymmetry between externalities imposed and suffered by each jurisdiction $\sum_{j \neq i}\left(\omega_{j} \beta_{j, i} \quad \omega_{i} \beta_{i, j}\right)$ cannot be too large in absolute value. For instance, in the case of two evenly populated jurisdictions, Eq. (4) is equivalent to $\left|\beta_{1,2} \quad \beta_{2,1}\right| \leq 1$, where 1 corresponds to the weight of the intrinsic preferences term in Eq. (2).

The assumption of symmetric externalities is a reasonable one for laws which regulate the exchange of goods or services whose bilateral trade flows are balanced; under this condition, even if legal fragmentation is not as costly for buyers as for sellers, the aggregate coordination cost will even out at the jurisdiction level. Conversely, if there are exchange imbalances, differences in product liability and accounting rules will be more costly for the exporting firms and for the investors of the country with a current account surplus. In addition to balanced trade flows, the reciprocality of externalities requires that the loss of competition due to transaction costs have a similar impact on both countries. This condition could be violated, for instance, if the demand elasticity is not the same in both jurisdictions, or if domestic competition is more intense in one jurisdiction than in the other. Coordination costs may also exhibit asymmetries if regulatory policies discriminate between foreign and domestic competitors. $^{21}$

The following simple example illustrates why asymmetries can be problematic under decentralization.

Example 1. Consider a federation of three jurisdictions with Euclidean intrinsic preferences such that $\theta=(-1,0,1)$ and

$\beta_{1,2}=\beta_{1,3}=\beta_{3,1}=\beta_{3,2}=0$ and $\beta_{2,1}=\beta_{2,3}=\beta$,

for some $\beta>0$. This pattern of externalities can model, for instance, the following scenario: a large number of workers in state 2 sell their labor to domestic firms but also to firms in states 1 and 3, while the residents of states 1 and 3 work only for domestic firms, and states 1 and 3 face an inelastic supply of workers. Under decentralization, $x^{\text {dec }}=(-1,0,1)$ : states 1 and 3 have no incentive to harmonize their labor laws and income taxation procedures to mitigate the coordination costs borne by the workers of state 2. Clearly, for $\beta$ sufficiently large, $x^{d e c}$ is socially worse than $(0,0,0)$.

An equally important source of asymmetry comes from the fact that the coordination costs borne by a jurisdiction may depend on which side of the policy spectrum it stands. For instance, the cost of having a different bargaining posture when negotiating with another country may not be the same for the tough member state as for the lenient one, although both of them would prefer the other to conform to its own posture. To make this point more explicitly, consider the following illustrative example. The incompatibility of traffic signs between two jurisdictions will confuse all drivers to a comparable extent, but different speed limits will probably have a different impact

\footnotetext{
21 The Article 30 and 36 of the Treaty Establishing the European Community, the Dormant Commerce Clause in the U.S., and Article III of the G.A.T.T. forbid discriminatory laws. See Farber (1997) or Ederington (2001) for more on discriminatory regulations.
} 
on the security and traffic flow in the low speed and high speed jurisdiction. This means that $\beta_{i, j}$ has different values, say, $\beta_{i, j}^{-}$and $\beta_{i, j}^{+}$, depending on the sign of $x_{i}-x_{j}$. The reciprocality condition would then become $\beta_{i, j}^{-}=\beta_{j, i}^{+}$if $x_{i} \leq x_{j}$, and vice versa. Fiscal competition can be viewed as one extreme case of such asymmetry for which $\beta^{-}<0$ and $\beta^{+}>0,{ }^{22}$ which explains why noncooperative behavior is socially more costly in a race to the bottom scenario than in a coordination problem.

\subsection{The magnitude of externalities}

A recurrent question in comparative law and in the trade literature is whether deeper economic integration and the network of interdependences it creates justify the harmonization of domestic policies by federal intervention. ${ }^{23}$ With our notations, this scenario corresponds to the case $\beta_{i, j} \rightarrow \infty$ for all $i, j$. The next proposition shows that the cost of decentralization vanishes as jurisdictions become highly interdependent. Hence, this model does not confirm the received wisdom that more severe externalities increase the com parative advantage of centralization.

Proposition 4. Let $\left(\beta^{n}\right)_{n \geq 0}$ be a sequence of matrices such that, for all $i \neq j, \beta_{i, j}^{n} \rightarrow+\infty$ and $\beta_{i, j}^{n}=O\left(\beta_{j, i}^{n}\right) .{ }^{24}$ Given $\left(V_{i}\right)_{i \in I}$ and $W$, let $x_{n}^{\text {dec }}$ be a decentralized equilibrium for the externality matrix $\beta^{n}$, let $x_{n}^{*}$ be a Pareto improving policy (not necessarily uniform), and let $U_{n}^{\text {dec }}$ and $U_{n}^{*}$ denote the corresponding profile of welfare. Then $U_{n}^{\text {dec }}-U_{n}^{*} \rightarrow 0$.

The condition that for all $i \neq j, \beta_{i, j}^{n}=O\left(\beta_{j, i}^{n}\right)$, which means that $\beta_{i, j}^{n}$ and $\beta_{j, i}^{n}$ tend to infinity at a similar rate, is reminiscent of the reciprocality condition of Proposition 2. One can easily adapt Example 1 to show that for $I \geq 3$, decentralization can be arbitrarily costly when this symmetry condition is not satisfied. ${ }^{25}$ Observe that since we do not require the Pareto improving policy $x_{n}^{*}$ to be uniform, Proposition 4 means that as the degree of interdependence increases in an asymptotically symmetric fashion, decentralization gets arbitrarily close to the Pareto frontier. The reason is that when the need for coordination becomes crucial and reciprocal, the incentives faced by local policy makers induce enough voluntary harmonization so that little gains can be expected from a central intervention.

Economists and legal scholars have documented numerous episodes of spontaneous legal harmonization during periods of economic and political integration. Prominent examples include the laws of international sales of goods after the World War II; the adoption of the Uniform Sales Act or the Model Penal Code in the U.S.; or the Law Merchant in medieval Europe. In all these cases, harmonization emerged as an equilibrium of a coordination game rather than as the result of a coercive top down intervention. ${ }^{26}$ Likewise, languages are social conventions which require a lot of coordination. Yet, most languages develop without any central authority. As Friedman and Friedman (1980) (p. 25) put it, "language ... is a complex structure that is continually changing and developing. It has a well defined order, yet no central body planned it."

Decentralization is clearly also optimal when externalities are negligible. So Proposition 4 implies that contrary to the case of

\footnotetext{
22 The high-tax country wants the low-tax country to choose a tax rate closer to its own, so $\beta<0$, while the low-tax country prefers to have the high tax country raise its tax rate even further, so $\beta^{+}>0$.

23 See, e.g., Lando (2000) and Rodrik (2004) for two different views on the question.

24 For two positive sequences $\left(u_{n}\right)_{n}$ and $\left(v_{n}\right)_{n}, u_{n}=O\left(v_{n}\right)$ if limsup $\frac{u_{n}}{v_{n}}<+\infty$.

25 In Example 1, if we assume quadratic preferences and set $\beta_{2,1}=\beta_{2,3}=b_{n}$ and $\beta_{i, j}=$ $B_{n}$ for all other $i \neq j$, simple algebra shows that $x^{\text {dec }}=\left(\left(3 b_{n}\right)^{1}, 0,\left(3 b_{n}\right)^{1}\right)^{1}$ and $\left(U_{n}^{\text {dec }}\right)_{2} \rightarrow \infty$ whenever $B_{n} /\left(b_{n}\right)^{2} \rightarrow \infty$. In the case $I=2$, Proposition 8 shows that no symmetry condition is necessary.

26 See Berman (1965) and Honnold (1999) on international sales law, Ribstein and Kobayashi (1996) and Smythe (2008) on the diffusion of uniform laws in the U.S., and Kerr (1929) on the history of the Law Merchant. See also Cooper (1994) for more examples of spontaneous international policy coordination.
}

expenditure externalities, the cost of decentralization is not mono tonic in the magnitude of externalities. To understand this discrep ancy, one has to compare the effect of an increase in the externalities on the gap between the private and the social benefits of public good provision in the fiscal federalism case and on the gap between the private and the social benefits of policy harmonization in the coordination externality case. An increase in the magnitude of (positive) spillovers accruing from other jurisdictions increases the social returns from public good provision but decreases its private returns the usual free riding problem. In contrast, an increase in coordination costs increases both the private and the social returns from policy harmonization.

The proof of Proposition 4 basically shows that, as externalities increase, decentralized policies converge sufficiently rapidly towards a uniform policy. However, one cannot simply conclude that in the limit, decentralization is equivalent to unitarian centralization: the forces that determine which uniform policy is implemented are not the same under the two regimes. Under decentralization, policies are determined by the strategic interactions generated by the patterns of interjurisdictional interdependencies. It turns out that if the latter are sufficiently reciprocal, decentralized policies converge to the socially optimal policy as jurisdictions become increasingly interdependent.

Proposition 5. Under the hypotheses of Proposition 4, if furthermore $\omega_{i} \beta_{i, j}^{n} \sim \omega_{j} \beta_{j, i}^{n}$ for all $i \neq j,{ }^{27}$ then $x_{n}^{\text {dec }}$ tends toward the socially optimal policy and $\sum_{i} \omega_{i} U_{n, i}^{\text {dec }}$ tends toward the optimal level of social welfare.

On the other hand, centralized policies are usually determined by voting rules which typically select the optimal policy only for very special profiles of preferences, ${ }^{28}$ or through top down bureaucratic procedures whose outcome can be biased by the interests of federal administrators or by their lack of information. Therefore, Proposition 5 implies the following

Corollary 1. Under the conditions of Proposition 5, if the centralized uniform policy $x^{c}$ is a function of the jurisdictions' intrinsic preferences $\left(V_{i}\right)_{i \in I}$ which is different from the socially optimal one, then decentral ization is socially preferred to centralization when externalities are sufficiently large.

\subsection{The elasticity of externalities}

Proposition 3 implies that when externalities are sufficiently asymmetric, centralization can improve on decentralization in aggregate terms. However, if side payments are not possible, asymmetries may compound the distributional problem of making all jurisdictions better off. The next proposition shows that when externalities are sufficiently elastic, a uniform rule will generate discontentment regardless of either the magnitude of externalities or the heterogeneity of preferences.

Proposition 6. If externalities are sufficiently elastic, there is no uniform policy which Pareto dominates a decentralized equilibrium.

Reciprocally, if externalities are sufficiently inelastic and if intrinsic preferences are Euclidean, then there is a profile of preferences $\theta$ and a decentralized equilibrium $x^{d e c}(\theta)$ which is Pareto dominated by a uniform policy.

Thus, Proposition 6 shows that elastic externalities support the argument for decentralization. Although the elasticity condition can be difficult to check precisely in practice, recall that $\frac{W^{\prime}(d) d}{W(d)}$ measures

\footnotetext{
27 For two positive sequences $\left(u_{n}\right)_{n}$ and $\left(v_{n}\right)_{n}, u_{n} \sim\left(v_{n}\right)$ if $\lim \frac{\left|u_{n} \quad v_{n}\right|}{u_{n}}=0$.

${ }^{28}$ For instance, if $\mathrm{X}=R$ and preferences are quadratic, the optimal uniform policy is the mean of the jurisdictions types, but the majority rule equilibrium is the median type.
} 
the relative rate of increase of coordination costs as a function of the relative increase in the distance/similarities between two policies. So the elasticity condition roughly means that when the number of discrepancies between two regulations is multiplied, say, by two, the additional compliance cost should be sufficiently large in relative terms. Qualitatively, Proposition 6 simply states the higher this rate of increase, the stronger the case for decentraliza tion. The intuition is that when externalities are sufficiently elastic, the marginal cost of having more distant policies becomes steep before the level of the coordination costs becomes too large. This prevents jurisdictions from implementing policies which are too incompatible.

Surprisingly, we shall see in Section 5 that the opposite case of completely inelastic externalities (i.e., $\frac{W^{\prime}(d) d}{W(d)} \rightarrow 0$ ) also supports the argument for decentralization. This case is not treated in Proposition 6 because completely inelastic externalities make preferences non convex.

\subsection{Robustness}

In this subsection, we show that the two main insights of the model that symmetric externalities increase the relative advantage of decentralization and that the cost of decentralization vanishes as the need for coordination increases still hold qualitatively without imposing any convexity or elasticity conditions on coordination costs. In this subsection, we assume that preferences are (3 times) differentiable, $W$ is strictly increasing, and intrinsic preferences are Euclidean. We restrict attention to the case of two jurisdictions and decompose the externality matrix into its symmetric part, $\beta_{S}=$ $\frac{\beta_{1,2}+\beta_{2,1}}{2}$, and its antisymmetric part, $\beta_{A}=\frac{\beta_{1,2}-\beta_{2,1}}{2}$.

Proposition 7. For all $V, W,\left(\theta_{1}, \theta_{2}\right)$, and $\beta_{S}$, there exists $\varepsilon>0$ such that for all decentralized equilibria $x$ at some $\beta_{A}$ such that $\left.\beta_{A} \in\right] 0, \varepsilon[$, there exists an equilibrium $x^{0}$ at $\beta_{A}=0$ such that $B(x)<B\left(x^{0}\right)$.

Observe that given $\beta_{S}$, the social welfare function $B$ does not depend directly on $\beta_{A}$, so Proposition 7 shows that the asymmetry of externalities increase the cost of decentralization. Moreover, since social welfare under centralization does not depend on $\beta$, Proposition 7 implies that if decentralization is dominated by a uniform policy at $\beta_{A}=0$, then it is also dominated by the same uniform policy for all $\beta_{A} \in[-\varepsilon, \varepsilon]$ for some $\varepsilon>0$.

The next proposition generalizes Proposition 4.

Proposition 8. Let $\beta^{n} \rightarrow \infty$, let $x_{n}^{\text {dec }}$ be a decentralized equilibrium and $x_{n}^{*}$ be a Pareto improving policy vector (not necessarily uniform), and let $U_{n}^{\text {dec }}$ and $U_{n}^{*}$ be the corresponding profiles of welfare, then $U_{n}^{\text {dec }}-U_{n}^{*} \rightarrow 0$.

\section{Discontinuities and network externalities}

For many types of policies such as technical standards (e.g., voltage, rail gage, and thickness of credit cards), dichotomous choices (e.g., ratification of an international convention and official recogni tion of a country), or public goods and services whose standardization can economize on fixed costs (e.g., drafting costs for laws, telecom munication infrastructure, and military equipment), what matters is not the degree of similarity between policies but which jurisdictions have the exact same policy.

The utility function specified in Eq. (1) can encompass this type of discontinuous network effects if it takes the following specific form:

$U_{i}(x)=V_{i}\left(x_{i}\right)-\sum_{j \neq i} \beta_{i, j} \delta\left(x_{i}, x_{j}\right)$ where the function $\delta: X \times X \rightarrow \mathbb{R}$ is defined by $\delta\left(x_{i}, x_{j}\right)=0$ if $x_{i}=x_{j}$, and $\delta\left(x_{i}, x_{j}\right)=1$ otherwise. ${ }^{29}$ However, our main result can be extended to a larger class of utility functions:

$U_{i}(x)=\Upsilon_{i}\left(x_{i},\left\{j \in I: x_{j}=x_{i}\right\}\right)$.

For this specification, $X$ is an arbitrary set; the function $\Upsilon_{i}$ : $X \times 2^{I} \rightarrow \mathbb{R}$ takes as its first argument the policy of jurisdiction $i$, and as its second argument the set of jurisdictions which have the same policy as jurisdiction $i, \Upsilon_{i}$ is increasing in its second argument in the inclusion sense.

In contrast to the case of smooth externalities, the decentralization game defined in Subsection 3.3 with the payoffs given by Eq. (6) can have a continuum of equilibria, some of them quite unsatisfactory. ${ }^{30}$ For this reason, the decentralization theorems in Section 4 must be qualified: there is no nontrivial condition on $\beta$ which guarantees that any decentralized equilibrium dominates centralization. However, the next proposition shows that if jurisdictions can easily coordinate on Pareto improving equilibria, the rationality of local jurisdictions is sufficient to achieve policy harmonization whenever it is socially beneficial.

Proposition 9. Suppose that for all $i, U_{i}$ is given by Eq. (6). If a uniform policy Pareto dominates a decentralized equilibrium, then this uniform policy is also a decentralized equilibrium.

Once again, in contrast with the free riding scenario, the absence of cooperation under decentralization does not justify a federal intervention in the form of coercive standardization. Proposition 9 stresses the importance of mechanisms, conventions, or institutions that help jurisdictions coordinate on a Pareto improving uniform equilibrium. Examples of such institutions include federal regulatory bodies such as NCCUSL or $\mathrm{ALI}^{31}$; international conventions such as UNIDROIT or UNCITRAL ${ }^{32}$; or international organizations such as the WTO or the IMF. These institutions promote legal and regulatory uniformity by proposing model laws whose adoption is then left to the discretion of its members. Likewise, international treaties and agreements result in some degree of harmonization but bind states only with their own consent. ${ }^{33}$

A technical remark is in order: as the game theoretic literature has highlighted (Konishi et al., 1997), the decentralization game defined in Section 3.3 may not have a pure strategy Nash equilibrium (henceforth PSNE) when payoffs exhibit discontinuous network effects as in Eq. (6). ${ }^{34}$ For instance, in the case of three jurisdictions

\footnotetext{
${ }^{29}$ Notice that such externalities could be described as completely inelastic in the sense of Definition 2 since $\delta\left(x_{i}, x_{j}\right)$ is the limit of $\left\|x_{i} \quad x_{j}\right\|^{\varepsilon}$ as $\varepsilon \rightarrow 0$.

${ }^{30}$ Even if all jurisdictions have the same ideal $p^{*}=\arg \max V_{i}$, any uniform policy can be an equilibrium if network effects are sufficiently important.

31 The National Conference of Commissioners on Uniform State Laws is a U.S. group which promotes legal uniformity across states. Since its founding in 1892, it has drafted over 200 model laws including the Uniform Sales Act. See Ribstein and Kobayashi (1996) on the N.C.C.U.S.L or Smythe (2008) on the Uniform Sales Act. The American Law Institute (ALI) is a group of U.S. legal practitioners that promotes the clarification, simplification, and uniformization of the American common law. It has drafted inter alia the Model Penal Code, which has been adopted in parts or in entirety by many states.

${ }^{32}$ The purpose of UNIDROIT, which counts 61 members, is to harmonize and coordinate private international law. UNCITRAL was established in 1966 "to promote the progressive harmonization and unification of international trade law." It now has 60 members. For instance, UNCITRAL developed the UN-convention on Contracts for the International Sales of Goods which has been adopted by more than 70 states.

33 See Snidal (1985); Farber (1997) or Posner (2006) for such an account of international law.

${ }^{34}$ The class of decentralization game with payoffs given by Eq. (6) is strategically equivalent to the class no-spillover, positive-externality game defined in Konishi et al (1997). However, their main existence result requires additional conditions, (anonimity, order-invariance, and order-preservation condition) which explains why a PSNE might not exist in general.
} 
(and $|X| \geq 3)^{35}$ with payoffs given by Eq. (5), if one of the two following conditions is satisfied:

$\left\{\beta_{1,2}>\beta_{1,3}, \beta_{2,3}>\beta_{2,1}\right.$ and $\beta_{3,1}>\beta_{3,2}$,

or $\beta_{1,2}<\beta_{1,3}, \beta_{2,3}<\beta_{2,1}$ and $\beta_{3,1}<\beta_{3,2}$.

then there exists a profile of intrinsic preferences $\left(V_{i}\right)_{i \in I}$ such that no PSNE exists. Reciprocally, if neither condition is satisfied and $\operatorname{argmax}_{i} \neq \varnothing$ for all $i$, a PSNE always exists. ${ }^{36}$ In words, the nonexistence of a PSNE requires a cycle in which each jurisdiction prefers to conform to its follower than to its predecessor. This suggests that the non existence of a PSNE arises under rather special circumstances. ${ }^{37}$

Characterizing the necessary and sufficient conditions for the existence of a PSNE in the general case is beyond the scope of this paper. However, we show in the following proposition that in the important cases of anonymous or (ordinally) symmetric network effects, a PSNE always exists.

Proposition 10. Let $\lambda \in \mathbb{R}_{+}^{|I|}$ be a vector positive weight and for all $i \in I$, let $V_{i}: X \rightarrow \mathbb{R}$ be function such that $\arg \max _{i} \neq \varnothing$. If the jurisdictions' welfare is either given by

$U_{i}(x)=V_{i}\left(x_{i}\right)+\lambda_{i} W\left(x_{i},\left|\left\{j \in I: x_{j}=x_{i}\right\}\right|\right)$,

where $W: X \times \mathbb{N} \rightarrow \mathbb{R}$ is increasingly in its second argument, or

$U_{i}(x)=V_{i}\left(x_{i}\right)-\lambda_{i} \sum_{j \neq i} \beta_{i, j}\left(x_{i}\right) \delta\left(x_{i}, x_{j}\right)$,

Where for all $i \neq j$ and all $p \in X, \beta_{i, j}(p)=\beta_{j, i}(p) \geq 0$, then a PSNE exists.

The first specification corresponds to network externalities which depend on the number but not on the identity of the jurisdictions which choose the same policy. Observe that it does not impose restrictions on the shape of intrinsic preferences $(V)$ or economies of scale $(W)$ and the latter can be policy specific. The existence of a PSNE in this case is a corollary of Konishi et al. (1997). The second specification is the ordinal extension of the reciprocality condition in Definition 2.

Moreover, in the cases of dichotomous choice, two jurisdictions, or "consecutive" preferences, ${ }^{38}$ both existence and efficiency are guaranteed.

Proposition 11. If either $(i)|X|=2$, or (ii) I=2, or (iii) the jurisdictions' welfare is given by

$U_{i}(x)=V_{i}\left(x_{i}\right)+W\left(x_{i},\left\{j \in I: x_{j}=x_{i}\right\}\right)$,

where $W: X \times 2^{I} \rightarrow \mathbb{R}$ is increasing in the inclusion sense in its second argument, $V_{i}$ is continuous, $X$ is compact and for all $p, q \in X, V_{i}(p)-V_{i}(q)$ is monotonic in $i$, then there exists a strong (and hence efficient) Nash equilibrium.

Case ( $i$ ) is a corollary of Konishi et al. (1997) and case (iii) is a corollary of Greenberg and Weber (1986).

\footnotetext{
35 If $I=2$ or $|X|=2$, a PSNE always exists, see proposition 10 .

${ }^{36}$ The proof of this result is available from the author upon request.

${ }^{37}$ Moreover, the conditions on the profile of intrinsic preferences $V$ necessary to obtain the nonexistence of a PSNE are such that each jurisdiction has a different most preferred policy and each policy is unacceptable for one jurisdiction.

38 The consecutiveness of preferences (condition (iii) of proposition 11) has the flavor of a single crossing condition: it essentially requires that jurisdictions can be ordered such that if $i \leq j \leq k$ and the best responses of $i$ and $k$ coincide at some strategy profile, then so must $j$ 's best response.
}

\section{Concluding remarks}

Our model shows that when the fiscal prisoner's dilemma turns into an administrative or legislative battle of the sexes, the compar ative statics of the comparison between centralization and decentral ization are qualitatively different and the welfare analysis shifts in favor of decentralization: the cost of decentralization vanishes as the need for coordination increases, and when externalities are reciprocal, decentralization dominates centralization irrespective of the magni tude of externalities and the heterogeneity of preferences.

The consequences of legal and regulatory heterogeneity lend themselves more easily to money metric measurements than do the adaptation costs associated with the unsuitability of laws to local needs. This asymmetry may have led federal administrators to overemphasize the need for harmonization. However, one cannot leap from the premise that globalization has increased the need for policy harmonization to the conclusion that coercive standardization is the best way to effect it. Our model suggests instead that decentralization can strike a satisfactory balance between respon siveness to local preferences and policy coordination regardless of the severity of costs generated by legal heterogeneity.

To conclude, we mention a couple of limitations of this model which point toward directions for further research. First, our model does not include the potential benefits of competitive regulatory federalism, which would tilt the balance further in favor of decentralization. ${ }^{39}$ Second, we do not explicitly model the legislative process $^{40}$ and the influence of lobbies. ${ }^{41}$ In Loeper (2010), we show that decentralization entails less policy harmonization when local policies are under the control of locally elected representatives. Finally, we do not allow for intermediate regimes between complete centralization and decentralization. In Loeper (2009), we allow for partial decentralization by letting citizens vote on the degree of local discretion left to local jurisdictions.

\section{Appendix A}

In what follows, for any differentiable function $f: X \rightarrow \mathbb{R}, \nabla f(p)$ denotes the gradient of $f$ at $p \in X$. For all $x \in X^{I}, X_{-i}$ denotes the policies of all jurisdictions $j \neq i$ and $\left(p, x_{-i}\right)$ denotes the vector of policies in which $x_{i}$ has been replaced by $p$. The following two Lemmas prove Proposition 1 .

Lemma 1. If preferences are differentiable, strictly convex and satisfy Assumption 1, a decentralized equilibrium exists. It is uniform if and only if $\arg \operatorname{maxV}_{i}$ is the same for all jurisdictions. It is inefficient otherwise.

All equilibria belong to some bounded set which depends only on $\left(V_{i}\right)_{i \in I}$.

For any $v \in X$ and any equilibrium $x, \nabla V_{i}\left(x_{i}\right) . v$ is non positive for some $i$ and non negative for others.

Proof. Since utility functions are differentiable and convex, the decentralized equilibria are the solutions of the FOC:

for $i=1 . . I, \nabla V_{i}\left(x_{i}\right)=\sum_{j} \beta_{i, j} \frac{W^{\prime}\left(\left\|x_{i}-x_{j}\right\|\right)}{\left\|x_{i}-x_{j}\right\|}\left(x_{i}-x_{j}\right)$,

with the convention that $\frac{W^{\prime}\left(\left\|x_{i}-x_{j}\right\|\right)}{\left\|x_{i}-x_{j}\right\|}\left(x_{i}-x_{j}\right)=0$ whenever $x_{i}=x_{j}$ ( since $W^{\prime}(0)=0$ by differentiability of $U_{i}$ ).

\footnotetext{
39 See, e.g., Mattei (1994) or Ogus (1999) on competitive federalism in the legal sphere. 40 Lockwood (2002) and Besley and Coate (2003) model explicitly legislative behavior at the federal level in a local public good model.

${ }^{41}$ A natural conjecture is that legal practitioners and domestic firms will lobby against legal harmonization if it threatens their local monopoly while international firms will lobby in favor of harmonization. See Ribstein and Kobayashi (1996) or Smythe (2008) for an empirical estimate of the influence of legal practitioners on state adoption of uniform laws. See also Redoano (2007) for a model of lobbying in a fiscal federalism setup.
} 
If all jurisdictions have the same ideal policy $p=\arg \max V_{i},(p, \ldots, p)$ is trivially an efficient equilibrium. The proof that it is the only equilibrium is omitted for the sake of brevity. Moreover, one can see from Eq. (7) that a uniform equilibrium cannot occur otherwise.

Assume now that jurisdictions do not all have the same ideal policy. Rearranging Eq. (7), we get

$x_{i}=\frac{\sum_{j} \frac{\beta_{i, j} W^{\prime}\left(\left\|x_{i}-x_{j}\right\|\right)}{\left\|x_{i}-x_{j}\right\|} x_{j}}{\sum_{j} \frac{\beta_{i, j} W^{\prime}\left(\left\|x_{i}-x_{j}\right\|\right)}{\left\|x_{i}-x_{j}\right\|}}+\frac{\nabla V_{i}\left(x_{i}\right)}{\sum_{j} \frac{\beta_{i, j} W^{\prime}\left(\left\|x_{i}-x_{j}\right\|\right)}{\left\|x_{i}-x_{j}\right\|}}$.

For any $v \in X$, let $n$ be such that $x_{i} . v \leq x_{n} . v$ for all $i \in I$. Taking the scalar product of Eq. (8) with $v$, we see that necessarily $\nabla V_{n}\left(x_{n}\right) . v \geq 0$. From Assumption 1, this implies that $x_{n}, v<a$ for some $a$ which depends only on $v$ and $V_{n}$. So for all $i \in I, x_{i} . v \leq a$. Since $v$ is arbitrary, this proves that the decentralized equilibria are necessarily in a bounded rectangle which depends only on $\left(V_{i}\right)_{i \in I}$. The convexity of $U_{i}$ completes the proof of the existence of a decentralized equilibrium.

Now let $m$ be such that $x_{i} . v \geq x_{m} . v$ for all $i \in I$, and consider the policy vector $x^{\prime}$ such that $x_{m}{ }^{\prime}=x_{m}+\varepsilon v, x_{n}{ }^{\prime}=x_{n}-\varepsilon v$ and $x_{i}{ }^{\prime}=x_{i}$ for $i \neq n, m$. We show that $x^{\prime}$ Pareto dominates $x$ for $\varepsilon$ sufficiently small: for all jurisdictions other than $n$ and $m$, their coordination costs decrease while their intrinsic utility stays constant. For jurisdictions $n$, changing $x_{n}$ has no first order effect since $x$ is an equilibrium while changing $x_{m}$ has a positive first order effect on coordination costs. A symmetric reasoning applies to $m$.

Lemma 2. If intrinsic preferences are Euclidean, $\theta \Rightarrow x^{\operatorname{dec}}(\beta, \theta)$ is onto on a neighborhood of $(0, . ., 0)$.

In the case of two jurisdictions with $\theta_{1} \neq \theta_{2}$, for any Pareto optimal policy $x^{*}$ and any decentralized equilibrium $x^{\text {dec }},\left\|x_{1}^{*}-x_{2}^{*}\right\|<\left\|x_{1}^{d e c}-x_{2}^{\text {dec }}\right\|$.

Proof. From the intermediate value theorem, $V^{\prime}$ is onto on $[0$, $\lim _{d \rightarrow+\infty} V^{\prime}(d)$ [. So for $\|v\|$ sufficiently small and for any $x_{i} \in X$, $\theta_{i}=\left(V^{\prime}\right)^{1}(\|v\|) \frac{v}{\|v\|}-x_{i}$ solves the equation $\nabla V_{i}\left(x_{i}\right)=v$ for $V_{i}\left(x_{i}\right)=$ $V\left(\left\|x_{i}-\theta_{i}\right\|\right)$. As shown earlier, $W^{\prime}(d) \rightarrow 0$ as $d \rightarrow 0$, so the right hand side of Eq. (7) tends to 0 as $x_{i}-x_{j} \rightarrow 0$ for all $i, j$. This proves that there exists $\left(\theta_{1}, . ., \theta_{I}\right)$ such that Eq. (7) is satisfied for any $x$ close enough to $(0, \ldots, 0)$.

If furthermore $I=2$, Eq. ( 7 ) implies that $x_{1}$ and $x_{2}$ belong to $\left[\theta_{1}, \theta_{2}\right]$ and

$\frac{V^{\prime}\left(\left\|x_{1}-\theta_{1}\right\|\right)}{\beta_{1,2}}=\frac{V^{\prime}\left(\left\|x_{2}-\theta_{2}\right\|\right)}{\beta_{2,1}}=-W^{\prime}\left(\left\|x_{1}-x_{2}\right\|\right)$.

Since utility functions are concave, a Pareto optimal policy maximizes $\omega_{1} U_{1}(y)+\omega_{2} U_{2}(y)$ for some $\omega_{1}>0$ and $\omega_{2}>0$ (the case $\omega_{1}=0$ or $\omega_{2}=0$ is obvious). The first order conditions imply that $x_{1}^{*}$ and $x_{2}^{*}$ belong to $\left[\theta_{1}, \theta_{2}\right]$ and

$\frac{V^{\prime}\left(\left\|x_{1}^{*}-\theta_{1}\right\|\right)}{\beta_{1,2}+\left(\omega_{2} / \omega_{1}\right) \beta_{2,1}}=\frac{V^{\prime}\left(\left\|x_{2}^{*}-\theta_{2}\right\|\right)}{\beta_{2,1}+\left(\omega_{1} / \omega_{2}\right) \beta_{1,2}}=-W^{\prime}\left(\left\|x_{1}^{*}-x_{2}^{*}\right\|\right)$.

Suppose $\left\|x_{1}^{*}-x_{2}^{*}\right\| \geq\left\|x_{1}-x_{2}\right\|$. Since $V^{\prime}$ is decreasing and $W^{\prime}$ is increasing, by comparing Eqs. (9) and (10), we see that $\left\|x_{i}-\theta_{i}\right\|<\| x_{i}^{*}-$ $\theta_{i} \|$ for $i=1,2$, which is impossible if $x_{1}, x_{2}, x_{1}^{*}$ and $x_{2}^{*}$ belong to $\left[\theta_{1}, \theta_{2}\right]$.

Lemma 3. Let $x$ be a decentralized equilibrium, $(p, \ldots, p)$ a uniform policy, $U^{\text {dec }}$ and $U^{c}$ the corresponding profile of utility, then if externalities are sufficiently elastic,

$U_{i}^{d e c}-U_{i}^{c} \geq\left[V_{i}\left(x_{i}\right)-V_{i}(p)-\nabla V_{i}\left(x_{i}\right) \cdot\left(x_{i}-p\right)\right]+\sum_{j \neq i} T_{i, j}$,

where $T_{i, j}=\beta_{i, j} W^{\prime}\left(\left\|x_{i}-x_{j}\right\|\right) \frac{\left\|x_{i}-p\right\|^{2}-\left\|x_{j}-p\right\|^{2}}{2\left\|x_{i}-x_{j}\right\|}$ and $T_{i, j}=0$ if $x_{i}=x_{j}$.
If externalities are sufficiently inelastic

$$
\begin{aligned}
U_{i}^{\text {dec }} & -U_{i}^{c} \leq V_{i}\left(x_{i}\right)-V_{i}(p)-\nabla V_{i}\left(x_{i}\right) \cdot\left(x_{i}-p\right) \\
& +\sum_{j \neq i} T_{i, j}+\frac{\varepsilon-2}{2} \sum_{j \neq i} \beta_{i, j} W\left(\left\|x_{i}-x_{j}\right\|\right)
\end{aligned}
$$

for some $\varepsilon<2$. If preferences are quadratic,

$U_{i}^{d e c}-U_{i}^{c}=\left\|x_{i}-p\right\|^{2}+\sum_{j} \beta_{i, j}\left[\left\|x_{i}-p\right\|^{2}-\left\|x_{j}-p\right\|^{2}\right]$.

Proof. Simple algebra yields

$$
\left(x_{i}-x_{j}\right) \cdot\left(x_{i}-p\right)-\frac{1}{2}\left\|x_{i}-x_{j}\right\|^{2}=\frac{1}{2}\left[\left\|x_{i}-p\right\|^{2}-\left\|x_{j}-p\right\|^{2}\right],
$$

Using successively the elasticity condition, Eqs. (7) and (11) we get

$$
\begin{aligned}
& \nabla V_{i}\left(x_{i}\right) \cdot\left(x_{i}-p\right)-\sum_{j} \beta_{i, j} W\left(\left\|x_{i}-x_{j}\right\|\right) \\
& \geq \nabla V_{i}\left(x_{i}\right) \cdot\left(x_{i}-p\right)-\frac{1}{2} \sum_{j} \beta_{i, j} W^{\prime}\left(\left\|x_{i}-x_{j}\right\|\right)\left\|x_{i}-x_{j}\right\| \\
& \geq \sum_{j} \beta_{i, j} W^{\prime}\left(\left\|x_{i}-x_{j}\right\|\right)\left[\frac{\left(x_{i}-x_{j}\right) \cdot\left(x_{i}-p\right)}{\left\|x_{i}-x_{j}\right\|}-\frac{1}{2}\left\|x_{i}-x_{j}\right\|\right] \\
& \geq \sum_{j} \beta_{i, j} W^{\prime}\left(\left\|x_{i}-x_{j}\right\|\right)\left[\frac{\left\|x_{i}-p\right\|^{2}-\left\|x_{j}-p\right\|^{2}}{2\left\|x_{i}-x_{j}\right\|}\right] .
\end{aligned}
$$

To get the desired inequality in the elastic case, substitute Eq. (12) into

$U_{i}^{d e c}-U_{i}^{c}=\left[V_{i}\left(x_{i}\right)-V_{i}(p)-\nabla V_{i}\left(x_{i}\right) \cdot\left(x_{i}-p\right)\right]$

$$
+\nabla V_{i}\left(x_{i}\right) \cdot\left(x_{i}-p\right)-\sum_{j} \beta_{i, j} W\left(\left\|x_{i}-x_{j}\right\|\right)
$$

If preferences are quadratic, $\frac{W^{\prime}(d) d}{W(d)} \equiv 2$ so Eq. (12) holds with equality. Simple algebra yields that the summand in Eq. (12) is $\beta_{i, j}\left(\left\|x_{i}-p\right\|^{2}-\left\|x_{j}-p\right\|^{2}\right)$ and the right hand side of Eq. (13) is $\left\|x_{i}-p\right\|^{2}$, which proves the quadratic case.

If externalities are sufficiently inelastic, using Definition 2, for some $\varepsilon<2$,

$$
\begin{gathered}
\sum_{j} \beta_{i, j} W\left(\left\|x_{i}-x_{j}\right\|\right)=\frac{\varepsilon}{2} \sum_{j} \beta_{i, j} W\left(\left\|x_{i}-x_{j}\right\|\right)+\frac{\varepsilon-2}{2} \sum_{j} \beta_{i, j} W\left(\left\|x_{i}-x_{j}\right\|\right) \\
\geq-\frac{1}{2} \sum_{j} \beta_{i, j} W^{\prime}\left(\left\|x_{i}-x_{j}\right\|\right)\left\|x_{i}-x_{j}\right\|+\frac{\varepsilon-2}{2} \sum_{j} \beta_{i, j} W\left(\left\|x_{i}-x_{j}\right\|\right) .
\end{gathered}
$$

The above inequality, together with Eqs. (7) and (11), implies that

$$
\begin{aligned}
& \nabla V_{i}\left(x_{i}\right) \cdot\left(x_{i}-p\right)-\sum_{j} \beta_{i, j} W\left(\left\|x_{i}-x_{j}\right\|\right)-\frac{\varepsilon-2}{2} \sum_{j} \beta_{i, j} W\left(\left\|x_{i}-x_{j}\right\|\right) \\
& \leq \sum_{j} \beta_{i, j} W^{\prime}\left(\left\|x_{i}-x_{j}\right\|\right)\left[\frac{\left(x_{i}-x_{j}\right) \cdot\left(x_{i}-p\right)}{\left\|x_{i}-x_{j}\right\|}-\frac{1}{2}\left\|x_{i}-x_{j}\right\|\right] \\
& \leq \sum_{j} \frac{1}{2} \beta_{i, j} W^{\prime}\left(\left\|x_{i}-x_{j}\right\|\right)\left[\frac{\left\|x_{i}-p\right\|^{2}-\left\|x_{j}-p\right\|^{2}}{\left\|x_{i}-x_{j}\right\|}\right] .
\end{aligned}
$$

and we substitute the following inequality in Eq. (14).

Proof of Proposition 2. With the notations of Lemma 3, if $\beta$ is reciprocal, for all $i \neq j, \omega_{i} T_{i, j}+\omega_{j} T_{j, i}=0$. So if $B^{\text {dec }}$ and $B^{c}$ denote the 
social welfare under decentralization and under the uniform policy $(p, \ldots, p)$,

$B^{d e c}-B^{c} \geq \sum_{i} \omega_{i}\left[V_{i}\left(x_{i}\right)-V_{i}(p)-\nabla V_{i}\left(x_{i}^{d e c}\right) \cdot\left(x_{i}^{d e c}-p\right)\right]$

which is nonnegative by concavity of $V_{i}$.

Proof of Proposition 3. If preferences are quadratic, Lemma 3 gives

$B^{d e c}-B^{c}=\sum_{i}\left(\omega_{i}+\sum_{j \neq i}\left(\omega_{i} \beta_{i, j}-\omega_{j} \beta_{j, i}\right)\right)\left\|x_{i}^{d e c}-p\right\|^{2}$,

which proves the sufficiency part. If $\omega_{i}+\sum_{j}\left(\omega_{i} \beta_{i, j}-\omega_{j} \beta_{j, i}\right)<0$ for some $i$, from Lemma 2, there exists $\theta$ such that $x_{i}^{\text {dec }}=\varepsilon$ for some $\varepsilon>0$ and $x_{j}^{d e c}=0$ for all $j \neq i$. From Eq. (15), the policy $(0, \ldots, 0)$ is socially preferred to $x^{\text {dec }}$.

In the following Lemma and in the Proof of Propositions 4 and 5, $x^{n}$ is a decentralized equilibrium for the profile of preferences $\left(\left(V_{i}\right)_{i \in I}, W, \beta^{n}\right)$.

Lemma 4. Under the condition of Proposition 4 , for all $i \neq j, \beta_{i, j}^{n} W^{\prime}\left(\| x_{i}^{n}-\right.$ $\left.x_{j}^{n} \|\right)$ is bounded, and $\beta_{i, j}^{n} W\left(\left\|x_{i}^{n}-x_{j}^{n}\right\|\right)$ and $\left\|x_{i}^{n}-x_{j}^{n}\right\|$ tend to 0 .

Proof. We will first show that $\beta_{i, j}^{n} W^{\prime}\left(\left\|x_{i}^{n}-x_{j}^{n}\right\|\right) \frac{\left(x_{i, k}^{n}-x_{j, k}^{n}\right) \cdot v}{\left\|x_{i}^{n}-x_{j}^{n}\right\|}$ is bounded for all $i \neq j$ and all $v \in X$. By letting $v$ be each of the vector of an orthonormal base of $X$, the first part of the Lemma follows. To clarify the argument, throughout the proof, we reorder the jurisdictions' indexes for each $n$ and $v$ so that $i \leq j \Rightarrow x_{i}^{n} . v \geq x_{j}^{n} . v$. With a slight abuse of notation, we define the sequence of federations $\left(\left(V_{i}^{n}\right)_{i \in I}, W, \beta^{n}\right)_{n>0}$ and the corresponding decentralized equilibria $\left(x^{n}\right)_{n \geq 0}$ consistently with this reindexation. The latter amounts to a symmetric permutation of rows and columns of $\beta$ and a permutation of $\left(V_{i}\right)_{i \in I}$ for each $v$ and $n$. Hence, we still have $\beta_{i, j}^{n} \rightarrow+\infty$ and $\beta_{i, j}^{n}=O\left(\beta_{j, i}^{n}\right)$ for all $i \neq j$ so the reindexation is w.l.o.g.

We proceed by induction on $i$. By construction $x_{1}^{n} \cdot v \leq x_{j}^{n} . v$, so from Eq. (7),

$\nabla V_{1}^{n}\left(x_{i}^{n}\right) \cdot v=\sum_{j} \beta_{1, j}^{n} \frac{W^{\prime}\left(\left\|x_{1}^{n}-x_{j}^{n}\right\|\right)}{\left\|x_{1}^{n}-x_{j}^{n}\right\|}\left(x_{1}^{n}-x_{j}^{n}\right) \cdot v$.

From Lemma 1, $x^{n}$ is bounded. Therefore, the left hand side of Eq. (16) is bounded and so is the right hand side. Since the latter is a sum of non negative scalars, each of them is bounded, which completes the case $i=1$.

Assume that the Lemma is true for $1, \ldots, i-1$. For any $n$, by construction $x_{i}^{n} . v \geq x_{j}^{n} . v$ for $i>j$ and $x_{i}^{n} . v \leq x_{j}^{n} . v$ for $i<j$. From Eq. (7),

$$
\begin{aligned}
& \nabla V_{i}\left(x_{i}^{n}\right) \cdot v-\sum_{j<i} \beta_{i, j}^{n} W^{\prime}\left(\left\|x_{i}^{n}-x_{j}^{n}\right\|\right) \frac{\left(x_{i}^{n}-x_{j}^{n}\right) \cdot v}{\left\|x_{i}^{n}-x_{j}^{n}\right\|} \\
& =\alpha \sum_{j>i} \beta_{i, j}^{n} W^{\prime}\left(\left\|x_{i}^{n}-x_{j}^{n}\right\|\right) \frac{\left(x_{i}^{n}-x_{j}^{n}\right) \cdot v}{\left\|x_{i}^{n}-x_{j}^{n}\right\|} .
\end{aligned}
$$

By hypothesis, for all $j<i, \beta_{j, i}^{n} W^{\prime}\left(\left\|x_{j}^{n}-x_{i}^{n}\right\|\right) \frac{\left(x_{j}^{n}-x_{i}^{n}\right) \cdot v}{\left\|x_{j}^{n}-x_{i}^{n}\right\|}$ is bounded. As $\beta_{i, j}^{n}=O\left(\beta_{j, i}^{n}\right)$, the symmetric term is bounded as well. Therefore, Eq. (17) and thus Eq. (18) are bounded. Since Eq. (18) is a sum of non negative terms, each of them is bounded which completes the induction.
Since $\beta_{i, j}^{n} W^{\prime}\left(\left\|x_{i}^{n}-x_{j}^{n}\right\|\right)$ is bounded, $W^{\prime}\left(\left\|x_{i}^{n}-x_{j}^{n}\right\|\right)$ and $\left\|x_{i}^{n}-x_{j}^{n}\right\|$ tend to 0 . Since $W$ is convex,

$\beta_{i, j}^{n} W\left(\left\|x_{i}^{n}-x_{j}^{n}\right\|\right) \leq \beta_{i, j}^{n} W^{\prime}\left(\left\|x_{i}^{n}-x_{j}^{n}\right\|\right)\left\|x_{i}^{n}-x_{j}^{n}\right\|$,

so from what precedes, $\beta_{i, j}^{n} W\left(\left\|x_{i}^{n}-x_{j}^{n}\right\|\right)$ tends to 0 .

Proof of Proposition 4. Lemma 4 implies that $U_{n}^{d e c}-\left(V_{i}\left(p^{n}\right)\right)_{i \in I} \rightarrow$ $(0, . ., 0)$ for some sequence of policy $\left(p^{n}\right)_{n \geq 0} \in X^{\mathbb{N}}$. Let $\left(y^{n}\right)_{n \geq 0}$ be a sequence of policy vectors which Pareto improve on $\left(x^{n}\right)_{n \geq 0}$ and denote $\left(U_{n}^{*}\right)_{n \geq 0}$ the corresponding sequence of utility profiles. Clearly, for all $i \neq j$, we must have $y_{i}^{n}-y_{j}^{n} \rightarrow 0$. Since we want to bound above $\left(U_{n}^{*}\right)_{n \geq 0}$, we can restrict attention to sequences such that $\beta_{i, j}^{n} W\left(\| y_{i}^{n}-\right.$ $\left.y_{j}^{n} \|\right) \rightarrow 0$. Therefore, there exists $q^{n} \in X^{\mathbb{N}}$ such that $U_{n}^{*}-\left(V_{i}\left(q^{n}\right)\right)_{i \in I} \rightarrow$ $(0, . ., 0)$. From Lemma $1, x^{n}$ is bounded and from Assumption 1, we can restrict attention to bounded sequences $\left(y^{n}\right)_{n \geq 0}$, so $p^{n}$ and $q^{n}$ are bounded too.

Let $p$ and $q$ be the limits of two converging subsequences of $p^{n}$ and $q^{n}$ and suppose $p \neq q$. The function $f_{i}(a)=V_{i}(a p+(1-a) q)$ is strictly concave on $[0,1]$. Since $f_{i}(0) \leq f_{i}(1)$, necessarily $f_{i}^{\prime}(0)=\nabla V_{i}(p)$. $(q-p)>0$. From Lemma 1 , for all $n, \nabla V_{i}\left(x_{i}^{n}\right) \cdot(q-p) \leq 0$ for some $i$. Taking the limit, $\nabla V_{i}(p) .(q-p) \leq 0$, a contradiction. So $p=q$ and $U^{d e c}=U^{*}$.

Proof of Proposition 5. Suppose $\omega_{i} \beta_{i, j}^{n} \sim \omega_{j} \beta_{j, i}^{n}$ for all $i \neq j$. Summing Eq. (7) over $i$, we get

$$
\sum_{i} \omega_{i} \nabla V_{i}\left(x_{i}^{n}\right)=\sum_{\{i, j\}}\left(\omega_{i} \beta_{i, j}^{n}-\omega_{j} \beta_{j, i}^{n}\right) W^{\prime}\left(\left\|x_{i}^{n}-x_{j}^{n}\right\|\right) \frac{\left(x_{i}^{n}-x_{j}^{n}\right)}{\left\|x_{i}^{n}-x_{j}^{n}\right\|} .
$$

From Lemma $4, \omega_{i} \beta_{i, j}^{n} W^{\prime}\left(\left\|x_{i}^{n}-x_{j}^{n}\right\|\right)$ is bounded for all $i \neq j$ and under our assumptions, it is equivalent to the symmetric term. As the difference of two equivalent and bounded sequences, the right hand side of Eq. (19) tends to zero. Therefore each local policy $x_{i}^{n}$ tends to the same policy $p^{*}$ defined by $\sum_{i} \omega_{i} \nabla V_{i}\left(p^{*}\right)=0$. From what precedes, for all $i, U_{n, i}^{\text {dec }} \rightarrow V_{i}\left(p^{*}\right)$.

One can readily check that $\left(p^{*}, \ldots, p^{*}\right)$ is the socially optimal uniform policy. Moreover, if $y^{n}$ denotes the socially optimal (not necessarily uniform) policy vector for the federation $\left(\left(V_{i}\right)_{i \in I}, W, \beta^{n}\right)$, necessarily $\beta_{i, j}^{n} W\left(\left\|y_{i}^{n}-y_{j}^{n}\right\|\right) \rightarrow 0$ for all $i \neq j .{ }^{42}$ Hence, $y^{n}$ tends towards a uniform policy which must be $\left(p^{*}, \ldots, p^{*}\right)$ and $U_{n, i}\left(y^{n}\right) \rightarrow V_{i}\left(p^{*}\right)$.

The next Lemma is instrumental to the Proof of Proposition 6. Lemma 5. If $W$ is sufficiently inelastic, then $\frac{W(d)}{d^{2}}$ is unbounded
around 0.

Proof. Suppose that for some $c>0$ and some $\Delta>0, W(d) \leq c d^{2}$ for all $d \in[0, \Delta]$. Since $W$ is sufficiently inelastic, $W^{\prime} \leq \epsilon c d$ for some $\varepsilon<2$. Integrating this inequality, we get $W \leq \frac{\epsilon}{2} c d^{2}$. By induction, $W \leq\left(\frac{\epsilon}{2}\right)^{n} c d^{2}$ for all $n$ so $W \equiv 0$, which is impossible by strict convexity of $U_{i}$.

Proof of Proposition 6. Suppose that externalities are sufficiently elastic. Let $x$ be a decentralized equilibrium. If $x$ is uniform, the result follows from Lemma 1 . If not, let $p \in X$ be a policy and $i$ be the jurisdiction whose local policy under decentralization is the farthest from $p$. Under the notation of Lemma $3, T_{i, j} \leq 0$ for all $j$. By strict concavity of $V_{i}, V_{i}\left(x_{i}\right)-V_{i}(p)-\nabla V_{i}\left(x_{i}\right) .\left(x_{i}-p\right)$ is negative, and thus $i$ strictly prefers $x$ to $(p, \ldots, p)$.

\footnotetext{
42 One can easily check that the socially optimal policy vector $y$ is a decentralized equilibrium for a confederation with an externality matrix $\gamma$ given by $\gamma_{i, j}=\omega_{i} \beta_{i, j}+$ $\omega_{j} \beta_{j, i}$. From Lemma $4,\left(\omega_{i} \beta_{i, j}^{n}+\omega j \beta_{j, i}^{n}\right) W\left(\left\|y_{i}^{n} \quad y_{j}^{n}\right\|\right) \rightarrow 0$.
} 
Suppose now that externalities are sufficiently inelastic and that intrinsic preferences are Euclidean. From Lemma 2, for any local policy $y \in X$ sufficiently small, there exists a vector of type $\theta$ such that the policy vector defined by $x_{i}=y$ for some $i$ and $x_{i}=-y$ for the other $i$ is a decentralized equilibrium. We will show that the uniform policy vector $(0, \ldots, 0)$ is Pareto better than $x$ for this federation. Under the notation of Lemma $3, T_{i, j}=0$ for all $i, j$. Since $V$ is twice differentiable,

$V\left( \pm y-\theta_{i}\right)-V\left(\theta_{i}\right)-\nabla V_{i}\left( \pm y-\theta_{i}\right) \cdot y=O\left(\|y\|^{2}\right)$.

From Lemma $5,\left(\frac{\varepsilon}{2}-1\right) \frac{W(2\|y\|)}{\|y\|^{2}}$ is negative and unbounded as $y \rightarrow 0$. Therefore, summing up all the terms in Lemma 3, we have $U_{i}^{\text {dec }}-$ $U_{i}^{c}<0$ for all $i$ and for $y$ sufficiently close to 0 .

Proof of Proposition 7. Since $V$ and $W$ are differentiable, a decen tralized equilibrium $x$ satisfies Eq. (7), which implies that $x_{1}$ and $x_{2}$ belong to the segment $\left[\theta_{1}, \theta_{2}\right]$. Therefore, to simplify notations, we rewrite Eq. (7) in one dimension with the convention that $\theta_{1}<\theta_{2}$ (and thus $\theta_{1}<x_{1}<x_{2}<\theta_{2}$ ):

$V^{\prime}\left(x_{1}-\theta_{1}\right)+\beta_{1} W^{\prime}\left(x_{2}-x_{1}\right)=V^{\prime}\left(\theta_{2}-x_{2}\right)+\beta_{2} W^{\prime}\left(x_{2}-x_{1}\right)=0$

From the implicit function theorem, there exists $\varepsilon>0$ and a smooth function $\left(x_{1}, x_{2}\right)\left(\beta_{A}\right)$ such that for all $\beta_{A} \in[-\varepsilon, \varepsilon],\left(x_{1}, x_{2}\right)\left(\beta_{A}\right)$ satisfies Eq. (20). Totally differentiating Eq. (20), we get

$\frac{\partial x_{1}}{\partial \beta_{A}} V^{\prime \prime}\left(x_{1}-\theta_{1}\right)+\left(\frac{\partial x_{2}}{\partial \beta_{A}}-\frac{\partial x_{1}}{\partial \beta_{A}}\right) \beta_{1} W^{\prime \prime}\left(x_{2}-x_{1}\right)+\frac{1}{2} W^{\prime}\left(x_{2}-x_{1}\right)=0$, $-\frac{\partial x_{2}}{\partial \beta_{A}} V^{\prime \prime}\left(\theta_{2}-x_{2}\right)+\left(\frac{\partial x_{2}}{\partial \beta_{A}}-\frac{\partial x_{1}}{\partial \beta_{A}}\right) \beta_{2} W^{\prime \prime}\left(x_{2}-x_{1}\right)-\frac{1}{2} W^{\prime}\left(x_{2}-x_{1}\right)=0$.

Differentiating the two equations above, we obtain

$$
\begin{gathered}
0=\frac{\partial^{2} x_{1}}{\partial \beta_{A}^{2}} V^{\prime \prime}\left(x_{1}-\theta_{1}\right)+\left(\frac{\partial x_{1}}{\partial \beta_{A}}\right)^{2} V^{\prime \prime \prime}\left(x_{1}-\theta_{1}\right) \\
+\left(\frac{\partial^{2} x_{2}}{\partial \beta_{A}^{2}}-\frac{\partial^{2} x_{1}}{\partial \beta_{A}^{2}}\right) \beta_{1} W^{\prime \prime}\left(x_{2}-x_{1}\right)+\left(\frac{\partial x_{2}}{\partial \beta_{A}}-\frac{\partial x_{1}}{\partial \beta_{A}}\right)^{2} \beta_{1} W^{\prime \prime \prime}\left(x_{2}-x_{1}\right) \\
+\frac{1}{2}\left(\frac{\partial x_{2}}{\partial \beta_{A}}-\frac{\partial x_{1}}{\partial \beta_{A}}\right) W^{\prime \prime}\left(x_{2}-x_{1}\right)+\frac{1}{2}\left(\frac{\partial x_{2}}{\partial \beta_{A}}-\frac{\partial x_{1}}{\partial \beta_{A}}\right) \beta_{1} W^{\prime \prime}\left(x_{2}-x_{1}\right)
\end{gathered}
$$

and

$$
\begin{gathered}
0=-\frac{\partial^{2} x_{2}}{\partial \beta_{A}^{2}} V^{\prime \prime}\left(\theta_{2}-x_{2}\right)-\left(\frac{\partial x_{2}}{\partial \beta_{A}}\right)^{2} V^{\prime \prime \prime}\left(\theta_{2}-x_{2}\right) \\
+\left(\frac{\partial^{2} x_{2}}{\partial \beta_{A}^{2}}-\frac{\partial^{2} x_{1}}{\partial \beta_{A}^{2}}\right) \beta_{2} W^{\prime \prime}\left(x_{2}-x_{1}\right)+\left(\frac{\partial x_{2}}{\partial \beta_{A}}-\frac{\partial x_{1}}{\partial \beta_{A}}\right)^{2} \beta_{2} W^{\prime \prime \prime}\left(x_{2}-x_{1}\right) \\
-\frac{1}{2}\left(\frac{\partial x_{2}}{\partial \beta_{A}}-\frac{\partial x_{1}}{\partial \beta_{A}}\right) W^{\prime \prime}\left(x_{2}-x_{1}\right)-\frac{1}{2}\left(\frac{\partial x_{2}}{\partial \beta_{A}}-\frac{\partial x_{1}}{\partial \beta_{A}}\right) W^{\prime \prime}\left(x_{2}-x_{1}\right) .
\end{gathered}
$$

From Eq. (20), $x_{1}-x_{2}$ must be an even function of $\beta_{A}$ so at $\beta_{A}=0$, $\frac{\partial x_{2}}{\partial \beta_{A}}=\frac{\partial x_{1}}{\partial \beta_{A}}$. Moreover, Eq. (20) implies that at $\beta_{A}=0, x_{1}-\theta_{1}=\theta_{2}-$ $x_{2}$. Substituting in Eqs. (21) and (22), we get that at $\beta_{A}=0$,

$$
\left(\frac{\partial^{2} x_{2}}{\partial \beta_{A}^{2}}-\frac{\partial^{2} x_{1}}{\partial \beta_{A}^{2}}\right)\left(-V^{\prime \prime}\left(x_{1}-\theta_{1}\right)+2 \beta_{S} W^{\prime \prime}\left(x_{2}-x_{1}\right)\right)=0
$$

which implies that at $\beta_{A}=0, \frac{\partial^{2} x_{2}}{\partial \beta_{A}^{2}}=\frac{\partial^{2} x_{1}}{\partial \beta_{A}^{2}} \cdot{ }^{43}$ Totally differentiating $B\left[\left(x_{1}, x_{2}\right)\left(\beta_{A}\right)\right]$,

$\overline{\partial B \partial \beta_{A}}=V^{\prime}\left(x_{1}-\theta_{1}\right) \frac{\partial x_{1}}{\partial \beta_{A}}-V^{\prime}\left(\theta_{2}-x_{2}\right) \frac{\partial x_{2}}{\partial \beta_{A}}+2 \beta_{S} W^{\prime}\left(x_{2}-x_{1}\right)\left(\frac{\partial x_{2}}{\partial \beta_{A}}-\frac{\partial x_{1}}{\partial \beta_{A}}\right)$

Substituting $\frac{\partial x_{2}}{\partial \beta_{A}}=\frac{\partial x_{1}}{\partial \beta_{A}}$ and $x_{1}-\theta_{1}=\theta_{2}-x_{2}$ in Eq. (23), we get $\frac{\partial B}{\partial \beta_{A}}\left(\beta_{A}=0\right)=0$. Differentiating again Eq. (23), we obtain

$$
\begin{aligned}
\frac{\partial^{2} B}{\partial \beta_{A}^{2}}= & V^{\prime \prime}\left(x_{1}-\theta_{1}\right)\left(\frac{\partial x_{1}}{\partial \beta_{A}}\right)^{2}+V^{\prime}\left(x_{1}-\theta_{1}\right) \frac{\partial^{2} x_{1}}{\partial \beta_{A}^{2}}+V^{\prime \prime}\left(\theta_{2}-x_{2}\right)\left(\frac{\partial x_{2}}{\partial \beta_{A}}\right)^{2} \\
& -V^{\prime}\left(\theta_{2}-x_{2}\right) \frac{\partial^{2} x_{2}}{\partial \beta_{A}^{2}}+2 \beta_{S} W^{\prime \prime}\left(x_{2}-x_{1}\right)\left(\frac{\partial x_{2}}{\partial \beta_{A}}-\frac{\partial x_{1}}{\partial \beta_{A}}\right)^{2} \\
& +2 \beta_{S} W^{\prime}\left(x_{2}-x_{1}\right)\left(\frac{\partial^{2} x_{2}}{\partial \beta_{A}^{2}}-\frac{\partial^{2} x_{1}}{\partial \beta_{A}^{2}}\right)
\end{aligned}
$$
$\begin{gathered}\text { Substituting } \\ \text { above, we get }\end{gathered} \frac{\partial x_{2}}{\partial \beta_{A}}=\frac{\partial x_{1}}{\partial \beta_{A}}, \frac{\partial^{2} x_{1}}{\partial \beta_{A}^{2}}=\frac{\partial^{2} x_{2}}{\partial \beta_{A}^{2}}$ and $x_{1}-\theta_{1}=\theta_{2}-x_{2}$

$\frac{\partial^{2} B}{\partial \beta_{A}^{2}}=V^{\prime \prime}\left(x_{1}-\theta_{1}\right)\left(\left(\frac{\partial x_{1}}{\partial \beta_{A}}\right)^{2}+\left(\frac{\partial x_{2}}{\partial \beta_{A}}\right)^{2}\right)$

so at $\beta_{A}=0, \frac{\partial^{2} B}{\partial \beta_{A}^{2}}<0$ and $\frac{\partial B}{\partial \beta_{A}}=0$, which completes the proof.

Proof of Proposition 8. As argued in the proof of Proposition 7, $x_{1}^{n}$ and $x_{2}^{n}$ belong to $\left[\theta_{1}, \theta_{2}\right]$ and thus are bounded. This implies that $U_{1}\left(x^{n}\right)$ is bounded below by $V_{1}\left(x_{2}^{n}\right)$, so $W\left(\left\|x_{1}^{n}-x_{2}^{n}\right\|\right) \rightarrow 0$ which in turn implies that $x_{2}^{n}-x_{1}^{n} \rightarrow 0$. The maximization of $U_{1}$ w.r.t. $x_{1}$ implies then that $\beta_{1,2}^{n} W\left(\left\|x_{1}^{n}-x_{2}^{n}\right\|\right) \rightarrow 0$. A symmetric reasoning shows that $\beta_{2,1}^{n} W\left(\| x_{2}^{n}-\right.$ $\left.x_{1}^{n}||\right) \rightarrow 0$. Therefore, there exists a bounded sequence of policy $\left(p^{n}\right)_{n \geq 1}$ such that

$U_{n}^{d e c}-\left(V\left(\left\|p^{n}-\theta_{1}^{n}\right\|\right), V\left(\left\|p^{n}-\theta_{2}^{n}\right\|\right)\right) \rightarrow(0,0)$.

Following the notations and the reasoning in the Proof of Proposition 4 , there exists a bounded sequence of policy $\left(q^{n}\right)_{n \geq 1}$ such that

$U_{n}^{*}-\left(V\left(\left\|q^{n}-\theta_{1}^{n}\right\|\right), V\left(\left\|q^{n}-\theta_{2}^{n}\right\|\right)\right) \rightarrow(0,0)$.

If $p$ and $q$ are the limits of two converging subsequences of $p^{n}$ and $q^{n}$, since $p$ belong to $\left[\theta_{1}, \theta_{2}\right]$ and since $V$ is decreasing, $(p, p)$ is Pareto optimal among uniform policy vectors so $p=q$. Since this is true for any converging subsequence, $U_{n}^{\text {dec }}-U_{n}^{*} \rightarrow 0$.

Proof of Proposition 9. Let $x$ be a decentralized equilibrium and $u=$ $(p, \ldots, p)$ be a Pareto improving uniform policy. For any $q \neq p, U_{i}(x) \geq U_{i}$ $\left(\left(q, x_{-i}\right)\right)$. Moreover, $\left\{j \neq i: z_{j}=q\right\}$ is weakly greater in the inclusion sense for $z=x$ than for $z=u$. So under our specification in Eq. (6), $U_{i}$ $\left(\left(q, x_{-i}\right)\right) \geq U_{i}\left(\left(q, u_{-i}\right)\right)$. By assumption, $U_{i}(u) \geq U_{i}(x)$. Summing up, we have $U_{i}(u) \geq U_{i}\left(\left(q, u_{-i}\right)\right)$, so $u$ is a decentralized equilibrium.

Proof of Proposition 10. In the case of anonymous network effects, Konishi et al. (1997) (Proposition 4.1 and Section 5) prove that the

\footnotetext{
43 Differentiating Eq. (20) w.r.t. $\beta_{S}$ and adding the two equations, we get $\left.\left(\frac{\partial x_{2}}{\partial \beta_{s}} \frac{\partial x_{1}}{\partial \beta_{s}}\right)\left(\begin{array}{ll}V^{\prime \prime}\left(x_{1}\right. & \theta_{1}\end{array}\right)+2 \beta_{s} W^{\prime \prime}\left(x_{2} \quad x_{1}\right)\right)+W^{\prime}\left(\begin{array}{ll}x_{2} & x_{1}\end{array}\right)=0$. Since $x_{2} \neq x_{1}, W^{\prime}\left(x_{2}\right.$ $\left.x_{1}\right) \neq 0$ so $V^{\prime \prime}\left(\begin{array}{ll}x_{1} & \theta_{1}\end{array}\right) \neq 2 \beta_{s} W^{\prime \prime}\left(\begin{array}{ll}x_{2} & x_{1}\end{array}\right)$.
} 
game admits a potential (see Monderer and Shapley, 1996). Likewise, in the case of symmetric network effects, if we denote

$P(x)=\sum_{i}\left(\frac{V_{i}\left(x_{i}\right)}{\lambda_{i}}+\frac{1}{2} \sum_{j} \beta_{i, j}(x) \delta\left(x_{i}-x_{j}\right)\right)$,

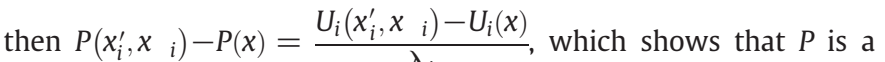
potential. For all $i \in I$, let $x_{i}^{*} \in \arg ^{\lambda} \max _{i}$ and let $X^{*}=\left\{x_{i}^{*}: i \in I\right\}$. Since $X^{*}$ is finite, in both cases, $P$ admits a maximum $x^{e}$ on $\left(X^{*}\right)^{I}$, and one can easily check that $x^{e}$ is a PSNE.

Proof of Proposition 11. The case $|X|=2$ is proved in Konishi et al. (1997) (Proposition 2.2). In the case $I=2$, observe that if $x=$ $\left(\arg \max V_{1}, \arg \max V_{2}\right)$ is Pareto efficient, it is also a strong Nash equilibrium. If not, Pareto efficient policy vectors are necessarily uniform and any uniform policy vector which Pareto dominates $x$ is a strong Nash equilibrium. In the case of (iii), one can readily check that the conditions ( $i$ ) and (ii) of Greenberg and Weber (1986) (Section V) are satisfied, so a strong Nash equilibrium exists.

\section{References}

Alesina, A., Angeloni, I., Etro, F., 2005a. International unions. The American Economic Review 95, 602-615.

Alesina, A., Angeloni, I., Schuknecht, L., 2005b. What does the European Union do? Public Choice 123 (3), 275-319.

Alesina, A., Spolaore, E., 1997. On the number and size of nations. Quarterly Journal of Economics 112 (4), 1027-1056.

Alonso, R., Dessein, W., Matouschek, N., 2007. When does coordination require centralization? The American Economic Review 98 (1), 145-179.

Baniak, A., Grazl, P., 2009. Interjurisdictional linkages and the scope for institutional harmonization. Typescript.

Beal, T., Nozaki, Y., Yang, J., 2001. Ghosts of the past: the Japanese History Textbook controversy. New Zealand Journal of Asian Studies 3 (2), 177-188.

Berkowitz, D., Pistor, K., Richard, J.F., 2003. Economic development, legality, and the transplant effect. European Economic Review 47 (1), 165-195.

Berman, H., 1965. The uniform law on international sale of goods. Law and Contemporary Problems 30 (2), 354-369.

Besley, T., Coate, S., 2003. Centralized versus decentralized provision of local public good: a political economy approach. Journal of Public Economics 87, 2611-2637.

Black, B., Kraakman, R., Tarassova, A., 2000. Russian privatization and corporate governance: what went wrong? Stanford Law Review 52, 1731-1808.

Bressand, A., 2010. European Integration and the Development of a European External Energy Policy. Global Public Policy Institute, Berlin. Paper Series No. 7.

Brown, C., Oates, W., 1987. Assistance to the poor in a federal system. J. Public Econ. 32 (3), 307-330.

Bucovetsky, S., Marchand, M., Pestieau, P., 1998. Tax competition and revelation of preferences for public expenditure. Journal of Urban Economics 44 (3), 367-390.

Carbonara, E., Parisi, F., 2007. The paradox of legal harmonization. Public Choice 132 (3-4), 367-400.

Coeure, B., Pisani-Ferry, J., 2003. One market, one voice? European arrangements in international economic relations. Paper Prepared for the Conference on "New Institutions for a New Europe", Vienna, 10-11 October 2003.

Cooper, R., 1994. International policy coordination. Journal of International Affairs 48 , 287-293.

Daniels, R.J., 1991. Harmonization of private rules between civil and common law jurisdictions: a Canadian perspective. McGill Law Journal 36, 130.

Djankov, S., La Porta, R., López de Silanes, F., Shleifer, A., 2003. Courts. Quarterly Journal of Economics 118, 453-517.

Ederington, J., 2001. International coordination of trade and domestic policies. The American Economic Review 91 (5), 1580-1593.

Epple, D., Nechyba, T., 2004. Fiscal decentralization. In: Henderson, V., Thisse, J.F. (Eds.), Handbook of Regional and Urban Economics (4). North-Holland, Amsterdam.

Ellingsen, T., 1998. Externalities vs. internalities: a model of political integration. J. Public Econ. 68 (2), 251-268 1.

Farber, D., 1997. Environmental federalism in a global economy. Virginia Law Review $83,1283-1319$.

Friedman, M., Friedman, R., 1980. Free to Choose: A Personal Statement. Harcourt Brace Jovanovich, New York.

Fudenberg, D., Tirole, J., 1991. Game Theory. MIT Press, Cambridge.

Ganuza, J.J., Gomez, F., 2008. Realistic standards: optimal negligence with limited liability. Journal of Legal Studies 37 (2), 577-594

Garoupa, N., Ogus, A., 2006. A strategic interpretation of legal transplants. The Journal of Legal Studies 35, 339-363.

Gordon, R., 1983. An optimal taxation approach to fiscal federalism. Quarterly Journal of Economics 98 (4), 567-586 Nov.
Gordon, R., Pelkmans, J., 1979. Challenges to Interdependent Economies: The Industrial West in the Coming Decade. McGraw-Hill, New-York.

Greenberg, J., Weber, S., 1986. Strong tiebout equilibrium under restricted preference domain. Journal of Economic Theory 38, 101-117.

Hansmann, H., Kraakman, R., 2001. The end of history for corporate law. Georgetown Law Review 89, 439.

Harstad, B., 2007. Harmonization and side payments in political cooperation. The American Economic Review 97 (3), 871-889.

Honnold, J., 1999. Uniform Law for International Sales under the 1980 United Nations Convention, 3rd ed. Kluwer Law International, The Hague, Netherlands.

Hurlburt, W.H., 1987. The harmonization of provincial legislation in Canada: the elusive goal. Canadian Business Law Journal 12, 387-396.

Ienaga, S., 1993. The glorification of war in Japanese education. International Security 18 (3), 113-133.

Kerr, C., 1929. The origin and development of the law merchant. Virginia Law Review 15 (4), 350-367.

Konishi, H., Le Breton, M., Weber, S., 1997. Pure strategy Nash equilibrium in a group formation game with positive externalities. Games and Economic Behavior 21 (12), 161-182.

Kox, H., Lejour, A., Montizaan, R., 2005. The free movement of services within the EU. CPB Netherlands Bureau for Economic Policy Analysis, Document 69.

Lando, O., 2000. Optional or mandatory Europeanization of contract law? European Review of Private Law 8, 59-69.

Laussel, D., Le Breton, M., 1998. Existence of Nash equilibria in fiscal competition models. Regional Science and Urban Economics 28, 283-296.

Legrand, P., 1996. European legal systems are not converging. International and Comparative Law Quarterly 45, 52-81.

Legrand, P., 1997. Against a European civil code. Modern Law Review 60 (1), 44-63.

Lockwood, B., 2002. Distributive politics and the cost of centralization. The Review of Economic Studies 69 (2), 313-337.

Loeper, A., 2008. Contractual federalism and strategy-proof coordination. CMS-EMS Discussion Paper No. 1521.

Loeper, A., 2009. Contractual Federal directives and local discretion. CMS-EMS Discussion Paper No. 1521.

Loeper, A., 2010. International coordination and national elections, Typesript.

Marciano, A., Josselin, J.M. (Eds.), 2002. The Economics of Harmonizing European Law. Edward Elgar Publishing, Northampton, MA.

Markesinis, B., 1994. Learning from Europe and learning in Europe. In: Markesinis, B. (Ed.), The Gradual Convergence. Clarendon Press, Oxford.

Mattei, U., 1994. Efficiency in legal transplants: an essay in comparative law and economics. International Review of Law and Economics 3, 3-19.

Mattei, U., 1997. Comparative Law and Economics. The University of Michigan Press, Ann Arbor, MI.

Mattli, W., Büthe, T., 2003. Setting international standards: technological rationality or primacy of power? World Politics 56 (1), 1-42.

Meunier, S., 2000. What single voice? European Institutions and E.U.-U.S. trade negotiations. International Organization 54 (1), 103-135.

Monderer, D., Shapley, L.S., 1996. Potential games. Games and Economic Behavior 14, 124-143.

Oates, W.E., 1972. Fiscal Federalism. Harcourt-Brace, New York.

Oates, W.E., 1999. An essay on fiscal federalism. Journal of Economic Literature 37 (3), 1120-1149.

Oates, W.E., 2005. Toward a second-generation theory of fiscal federalism. International Tax and Public Finance 12, 349-373.

Ogus, A., 1999. Competition between national legal systems: a contribution of economic analysis to comparative law. International and Comparative Law Quarterly 48, $405-418$.

Posner, E., 2006. International law: a welfarist approach. University of Chicago Law Review 73 (2), 487-543.

Putnam, R.D., 1988. Diplomacy and domestic politics: the logic of two-level games. International Organization 42 (3), 427-460.

Qian, Y., Weingast, B.R., 1997. Federalism as a commitment to preserving market incentives. The Journal of Economic Perspectives 11 (4), 83-92.

Rantakari, H., 2008. Governing adaptation. The Review of Economic Studies 75 (4), 1257-1285.

Redoano, M., 2007. Does Centralization Affect the Number and Size of Lobbies? Typesript.

Redoano, M., Scharf, K., 2004. The political economy of policy centralization: direct versus representative democracy. J. Public Econ. 88 (3-4), 799-817.

Ribstein, L.E., Kobayashi, B.H., 1996. An economic analysis of uniform state law. Journal of Legal Studies 25, 131-199.

Rodrik, D., 2004. Globalization and growth-looking in the wrong places. Journal of Policy Modeling 26 (4), 513-517.

Seabright, P., 1996. Accountability and decentralization in government: an incomplete contract model. Eur. Econ. Rev. 40 (1), 61-89.

Smaghi, L., 2004. A single EU seat in the IMF? Journal of Common Market Studies 42 (2), 229-248.

Smythe, D., 2008. Transaction costs, neighborhood effects, and the diffusion of the Uniform Sales Act, 1906-47. Review of Law \& Economics 4 (1), 341-372.

Snidal, D., 1985. Coordination versus prisoner's dilemma: implications for international cooperation and regimes. The American Political Science Review 79 (4), 923-942.

Solé, A., Sorribas, P., 2007. The effects of partisan alignment on the allocation of intergovernmental transfers: differences-in-differences estimates for Spain. J. Public Econ. 92, 2302-2319.

Strauss-Kahn, D., 2002. La Flamme et la cendre. Grasset, Paris. 
Teubner, G., 1998. Legal irritants: good faith in British law or how unifying law produces new divergences. Modern Law Review 61, 11-32.

Trubek, D., Galanter, M., 1974. Scholars in self-estrangement: some reflections on the crisis in law and development studies in the United States. Wisconsin Law Review 4, 1062-1101.

Wildasin, D., 1991. Income redistribution in a common labor market. The American Economic Review 81 (4), 757-774.
Wilson, J., 1986. A theory of interregional tax competition. Journal of Urban Economics 19 (3), 296-315.

Zodrow, G.R., Mieszkowski, P., 1986. Pigou, tiebout, property taxation, and the underprovision of local public goods. Journal of Urban Economics 19, 356-370.

Zweigert, K., Kötz, H., 1998. An Introduction to Comparative Law, 3rd ed. Oxford University Press, Oxford. 